University of Nebraska - Lincoln

DigitalCommons@University of Nebraska - Lincoln

2011

\title{
Oceanographic and atmospheric conditions on the continental shelf north of the Monterey Bay during August 2006
}

Steven R. Ramp

Soliton Ocean Services, Inc., sramp@solitonocean.com

Pierre F.J. Lermusiaux

Massachusetts Institute of Technology, pierrel@mit.edu

Igor Shulman

Stennis Space Center, igor.shulman@nrlssc.navy.mil

Yi Chao

California Institute of Technology

Rebecca E. Wolf

Naval Postgraduate School

See next page for additional authors

Follow this and additional works at: https://digitalcommons.unl.edu/usnavyresearch

Ramp, Steven R.; Lermusiaux, Pierre F.J.; Shulman, Igor; Chao, Yi; Wolf, Rebecca E.; and Bahr, Frederick L., "Oceanographic and atmospheric conditions on the continental shelf north of the Monterey Bay during August 2006" (2011). U.S. Navy Research. 42.

https://digitalcommons.unl.edu/usnavyresearch/42

This Article is brought to you for free and open access by the U.S. Department of Defense at DigitalCommons@University of Nebraska - Lincoln. It has been accepted for inclusion in U.S. Navy Research by an authorized administrator of DigitalCommons@University of Nebraska - Lincoln. 


\section{Authors}

Steven R. Ramp, Pierre F.J. Lermusiaux, Igor Shulman, Yi Chao, Rebecca E. Wolf, and Frederick L. Bahr 


\title{
Oceanographic and atmospheric conditions on the continental shelf north of the Monterey Bay during August 2006
}

\author{
Steven R. Ramp ${ }^{a, *}$, Pierre F.J. Lermusiaux ${ }^{b}$, Igor Shulman ${ }^{c}$, \\ Yi Chao ${ }^{d}$, Rebecca E. Wolf ${ }^{\mathrm{e}}$, Frederick L. Bahr ${ }^{\mathrm{f}}$ \\ a Soliton Ocean Services, Inc., Carmel Valley, CA 93924, United States \\ b Massachusetts Institute of Technology, Cambridge, MA 02139, United States \\ c Naval Research Laboratory, Stennis Space Center, MS 39529, United States \\ d Jet Propulsion Laboratory, California Institute of Technology, Pasadena, CA 91109, United States \\ e Naval Postgraduate School, Monterey, CA 93943, United States \\ f Monterey Bay Aquarium Research Institute, Moss Landing, CA 95039, United States
}

\section{A R T I C L E I N F O}

Available online 6 May 2011

Keywords:

Coastal circulation

Air/sea interaction

Upwelling

Ocean modeling and prediction

USA/West Coast/California/Monterey Bay

\begin{abstract}
A B S T R A C T
A comprehensive data set from the ocean and atmosphere was obtained just north of the Monterey Bay as part of the Monterey Bay 2006 (MB06) field experiment. The wind stress, heat fluxes, and sea surface temperature were sampled by the Naval Postgraduate School's TWIN OTTER research aircraft. In situ data were collected using ships, moorings, gliders and AUVs. Four data-assimilating numerical models were additionally run, including the Coupled Ocean/Atmosphere Mesoscale Prediction System $\left(\right.$ COAMPS $^{\circledR}$ ) model for the atmosphere and the Harvard Ocean Prediction System (HOPS), the Regional Ocean Modeling System (ROMS), and the Navy Coastal Ocean Model (NCOM) for the ocean.

The scientific focus of the Adaptive Sampling and Prediction Experiment (ASAP) was on the upwelling/relaxation cycle and the resulting three-dimensional coastal circulation near a coastal promontory, in this case Point Año Nuevo, CA. The emphasis of this study is on the circulation over the continental shelf as estimated from the wind forcing, two ADCP moorings, and model outputs. The wind stress during August 2006 consisted of 3-10 day upwelling favorable events separated by brief $1-3$ day relaxations. During the
\end{abstract}

\footnotetext{
* Corresponding author. Tel.: +1 8316592230.

E-mail address: sramp@solitonocean.com (S.R. Ramp).
} 
first two weeks there was some correlation between local winds and currents and the three models' capability to reproduce the events. During the last two weeks, largely equatorward surface wind stress forced the sea surface and barotropic poleward flow occurred over the shelf, reducing model skill at predicting the circulation. The poleward flow was apparently remotely forced by mesoscale eddies and alongshore pressure gradients, which were not well simulated by the models. The small, high-resolution model domains were highly reliant on correct open boundary conditions to drive these larger-scale poleward flows. Multiply-nested models were no more effective than well-initialized local models in this respect.

(c) 2011 Elsevier B.V. All rights reserved.

\section{Introduction}

The Adaptive Sampling and Prediction Experiment (ASAP) was launched during the summer of 2006 with the overall goal to learn how to deploy, direct, and utilize autonomous vehicles most efficiently to sample the ocean, assimilate the data into numerical models in real or near-real time, and predict future conditions with minimal error. A fleet of four Spray (Davis et al., 2002) and six Slocum gliders under autonomous control were deployed in late July to cooperatively sample a control volume in an upwelling center for a period of 30 days. The scientific focus was to close the heat budget in a three-dimensional upwelling center and thus illuminate the along- and across-shore transport and fundamental dynamics of the process. The glider fleet patrolled the boundaries and interior of the control volume and a research aircraft observed the fluxes through the sea surface. Two bottom-mounted acoustic Doppler current profilers (ADCPs) were deployed on the 54 and $92 \mathrm{~m}$ isobaths to monitor the currents over the continental shelf and provide ground truth for the newer, more innovative instrumentation.

Based on previous work, the evolution of coastal upwelling near Point Año Nuevo can be described as follows: By comparing aircraft-sensed winds and SST, Ramp et al. (2009) determined that cold water $<13^{\circ} \mathrm{C}$ first appears at the Point within $12-24 \mathrm{~h}$ of the onset of upwelling-favorable winds. As the wind continues to blow for 5-10 days, a cold plume forms which may move further offshore or turn southward across the Monterey Submarine Canyon (MSC) (Rosenfeld et al., 1994; Ramp et al., 2005; Haley et al., 2009). A warm, fresh, anticyclonic feature (the "Monterey Bay Eddy" or MBE) often exists offshore, which interacts with the cold plume in some complex way (Rosenfeld et al., 1994; Paduan and Rosenfeld, 1996; Ramp et al., 2005). It has now been determined during the second Autonomous Ocean Sensing Network (AOSN-II) experiment that the position and strength of the anticyclonic feature can determine the bifurcation of the upwelling front (Ramp et al., 2009). When the MBE lies offshore, the upwelling plume is transported offshore by Ekman advection. When the feature has moved inshore, the combination of blocking and geostrophic current force the plume to move southward across the mouth of the bay. Time series of sea surface temperature from aircraft and AVHRR images show that the MBE moves rapidly onshore during wind relaxation events and retreats back offshore when the winds re-intensify (Rosenfeld et al., 1994; Ramp et al., 2005). Moored observations however have also shown an onshore and southward translation of the MBE without a wind relaxation (Ramp et al., 1997a,b). The mechanism for this across-shore eddy translation is thus not fully understood. How far the eddy forcing penetrates up onto the continental shelf has also not been well observed. Since these features are more than $1000 \mathrm{~m}$ deep (Ramp et al., 1997a,b) one expects that due to rotational rigidity, their penetration onto the shelf would be limited, similar to Gulf Stream Warm Core Rings (Ramp, 1989).

Much less obvious is the ocean dynamics during the wind relaxation events, defined here to be periods of poleward or no wind. During these events, barotropic poleward flows typically appear over the continental shelf along the west coast of the U.S. Observational examples of this include the Coastal Ocean Dynamics Experiment (CODE) region off Point Arena, CA (Winant et al., 1987; Lentz, 1987), 
further south off Point Sur, CA (Chelton, 1984; Ramp and Abbott, 1998), and south of Cape Blanco, OR (Ramp and Bahr, 2006). Recent modeling studies attribute this current to a poleward alongshore pressure gradient force (PGF) south of the major headlands, which encourages both poleward flow near the coast and onshore transport in geostrophic balance with the poleward PGF (Gan and Allen, 2002a,b). Since these gradients are typically remotely forced over very large scales, there is usually less coherence between local winds and currents during relaxation events than during upwelling events, making them much more difficult to reproduce with local, high-resolution numerical models. In fact, uncertainties of coherent structures estimated by model simulations (Lermusiaux, 2006; Lermusiaux et al., 2006) during such relaxation periods are large.

In this paper, a rigorous description of the currents over the continental shelf just south of Point Año Nuevo and their response to local and remote forcing is presented using in situ data from moored ADCPs, remotely sensed data from a low-flying aircraft, and model output from three numerical models run during the ASAP experiment. The paper is intended to set the stage for a more detailed dynamical analysis of the three-dimensional circulation in the ASAP region using all available assets. Following a basic description of the observational tools and techniques in Section 2, the observed winds and currents are described in Section 3 and compared using correlation and spectral analysis. The three models, including their grids, initialization and data assimilation techniques, and computational schemes are set forth in Section 4, where the model outputs are also quantitatively compared with the observed currents at the two ADCP locations. The results are discussed in Section 5 and summarized in Section 6.

\section{Data and methods}

\subsection{Real-time ADCP data}

The moorings deployed for the August 2006 experiment consisted of two $300 \mathrm{kHz}$ acoustic Doppler current profilers (ADCPs) in trawl-resistant bottom mounts (TRBMs) located $6.55 \mathrm{~km}$ apart. ADCP 1 was located at $36^{\circ} 55.336^{\prime} \mathrm{N}, 122^{\circ} 07.344^{\prime} \mathrm{W}, 54 \mathrm{~m}$ depth, and ADCP 2 was located at $36^{\circ} 53.683^{\prime} \mathrm{N}$, $122^{\circ} 11.244^{\prime} \mathrm{W}, 92 \mathrm{~m}$ depth (Fig. 1 ). The data were sampled in 4 -m bins from the bottom to the surface, however the uppermost 3 bins $(12 \mathrm{~m})$ were lost due to side-lobe reflection. Bottom-mounted moorings

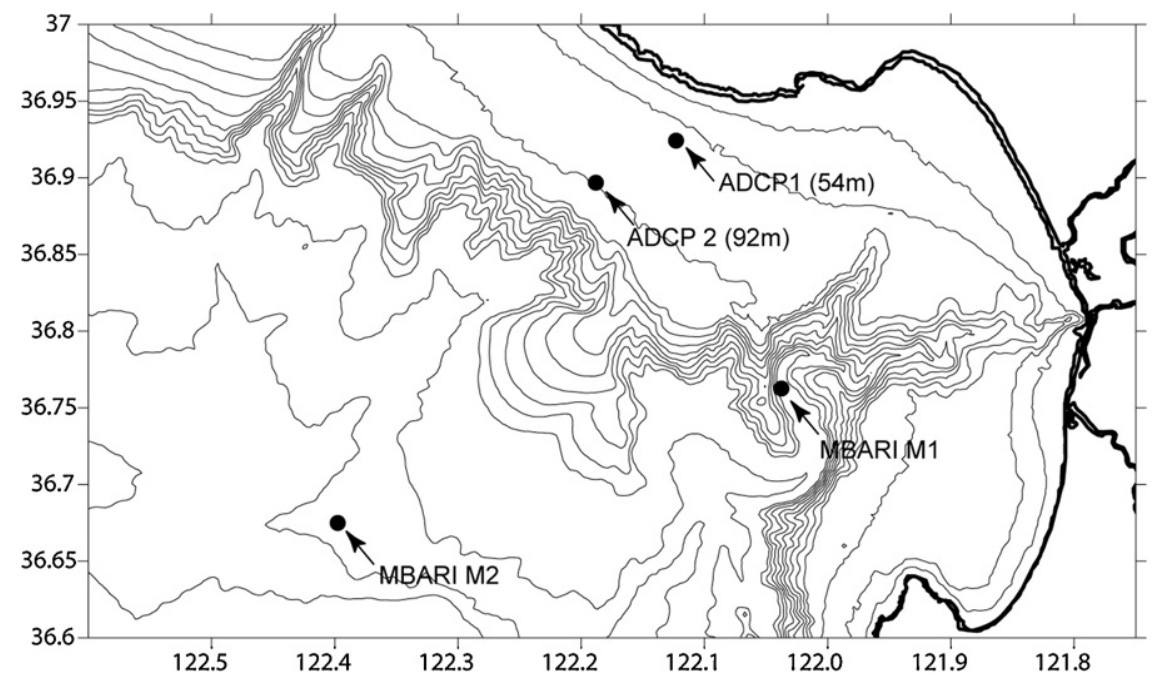

Fig. 1. Map of the greater Monterey Bay region showing the locations of the ADCPs and wind buoys. On the continental shelf, the 20,50 , and $100 \mathrm{~m}$ contours are shown. 
are advantageous because they have no extraneous movement, and allow faster sampling and less averaging to achieve a good signal-to-noise ratio than a surface mooring. The basic 1 -min time series were obtained by ensemble averaging 601 -s pings in the instrument. Subsequent averaging and filtering to separate the frequency bands of interest were accomplished in the laboratory. An inverseFourier truncation method was used to remove internal waves with periods of $5 \mathrm{~h}$ or less. The residual time series were filtered again with the half-power point at $33 \mathrm{~h}$ (Beardsley et al., 1985) to separate the tidal and inertial motions from the wind forced, mesoscale, and mean currents. A principal axis technique was used to rotate the $u$ and $v$ components into across- and alongshelf components. This method of rotation ensures that a minimum of the alongshelf flow will be translated into the acrossshelf flow (Kosro, 1987). The principal axis rotation agreed with the local orientation of the bathymetry and yielded angles of $-58^{\circ}$ for ADCP 1 and $-48^{\circ}$ for ADCP 2 , with respect to true north.

A novel aspect of the experiment was that the data were transmitted back to the laboratory in real-time using Benthos Telesonar acoustic modems operating on a Seaweb undersea network (Rice and Green, 2008). This system allowed the ADCPs to be bottom-mounted in TRBMs, completely free of surface motion, but still able to transmit the data to the laboratory in real time. The ADCPs were programmed to send back the most recent estimate via satellite link, every $10 \mathrm{~min}$. A redundant system with two surface gateway buoys and three intermediate relay points was used to ensure reliability and keep the acoustic power output levels low. The data were moved from the gateway buoys to the Naval Postgraduate School via the iridium satellite communications network. The system worked flawlessly for 18 days but then failed due to (a) sea water incursions into the iridium antennas and (b) low power on the surface buoys. The real-time current data were used to understand and adapt the sampling paths of the ASAP gliders and AUVs.

\subsection{Wind observations}

The wind time series was recorded by buoy M2 located at $36^{\circ} 42^{\prime} \mathrm{N}, 122^{\circ} 23^{\prime} \mathrm{W}$ at the mouth of the Monterey Bay and maintained by the Monterey Bay Aquarium Research Institute (MBARI). Buoy M2 was slightly farther away from the two ADCPs than similar buoy M1, but was less sheltered by coastal topography and therefore more representative of the offshore winds. The wind time series were low-pass filtered with the same 33 -h filter as the ADCP data and rotated $22^{\circ}$ into the along-and across-shore components, aligned with the coastal mountain range. This is a different rotation than was used for the currents to match the local bottom topography.

\subsection{Aircraft data}

The airborne measurements during ASAP were obtained using the TWIN OTTER aircraft owned and operated by the Center for Interdisciplinary Remotely-Piloted Aircraft Studies (CIRPAS) at the Naval Postgraduate School. Thirteen flights were conducted daily between August 1 and 15, 2006 (except August 6 and 13) at an altitude of nominally $33 \mathrm{~m}$ above the sea surface. The low altitude was chosen to pass beneath the stratus cloud deck that often covers the Monterey Bay in summer, and to minimize the vertical divergence in the heat and momentum flux observations. The flight path covered the area from the center of the bay north to about Pigeon Point, out to $35 \mathrm{~km}$ offshore. This took about $2.5 \mathrm{~h}$ to execute beginning usually about $10 \mathrm{am}$ local time, subject to weather conditions. To collect air/sea fluxes at high temporal and spatial resolution, the sample area focused on the region surrounding Point Año Nuevo where the upwelling plume was first developing. The atmospheric parameters sampled by the aircraft included air temperature and dew point, atmospheric pressure, wind speed and direction, the turbulent fluxes of heat and momentum, and total particle number, as well as aerosol and cloud/fog droplet size distributions. In the ocean, sea surface temperature (SST), ocean-leaving radiance at 193 wavelengths, sun glint, and surface roughness were observed. The SST, air temperature and dew point, and wind data were made available for model assimilation in near-real time, while the other parameters required additional post-processing. 


\section{Observational results}

\subsection{Atmospheric forcing}

August 2006 was a fairly typical summer month off central California with periods of sustained upwelling favorable winds at about $10 \mathrm{~m} \mathrm{~s}^{-1}$ separated by brief periods of weak poleward or no winds (Fig. 2). At buoy M2, upwelling-favorable wind events with approximately equal strength took place during August 1-3, 8-12, 16-25, and 28-31. Poleward winds less than $2.5 \mathrm{~m} \mathrm{~s}^{-1}$ blew during August $4-7,13-15$, and 26-27. A unique strength of the ASAP data set was the spatial distribution of the wind stress as sampled by the TWIN OTTER aircraft. The wind stress was computed from the bulk
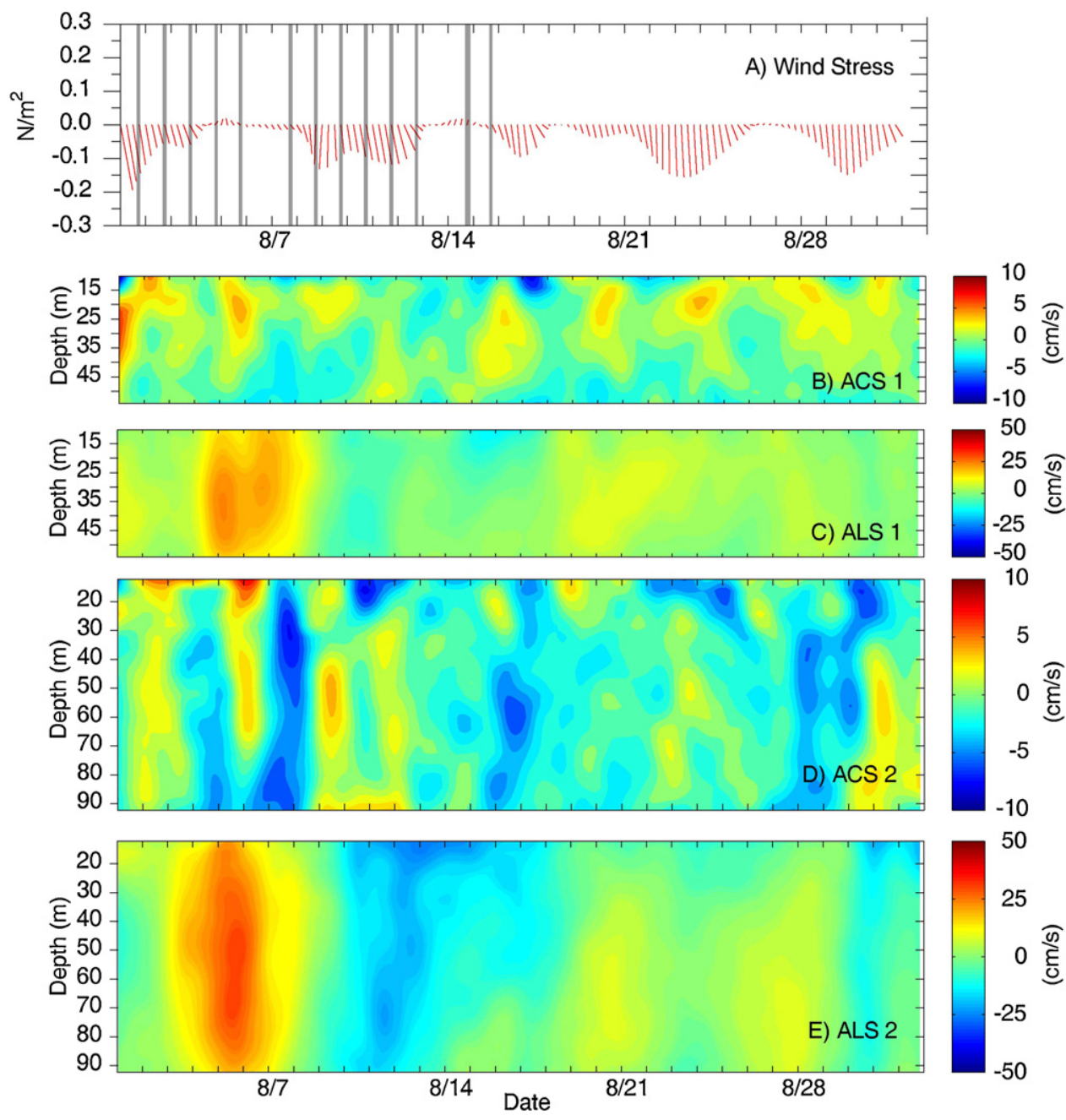

Fig. 2. Time series of (a) wind stress from MBARI buoy M2, (b) across-shore current at ADCP 1, (c) alongshore current at ADCP 1, (d) across-shore current at ADCP 2, and (e) alongshore current at ADCP 2. The scale of the $y$-axis is the same for both ADCPs, with the difference in plot height reflecting the difference in water depth. The velocity scales are different for the across- and alongshore current components to better illustrate the much smaller across-shore flow. A positive sign indicates poleward and onshore flow. The vertical gray bars on the wind stress plot indicate the time of the TWIN OTTER over-flights. The vectors indicate the direction the wind is blowing towards. 
aerodynamic flux formulae using the wind speed, air temperature, relative humidity, air pressure, sea surface temperature, and altitude as inputs (Fairall et al., 1996). A turbulent boundary layer was assumed and Monin-Obukov similarity theory was used to adjust the stress down to $10 \mathrm{~m}$ height. The assumption was validated by the bulk Richardson Number $\left(R_{i}\right)$ which was small and/or negative throughout, indicating a fully turbulent boundary layer. The only exception occurred on August 5 , an exceptionally calm day, but $R_{i}$ was still less than 10 and the same method was used to compute the stress.

A selection of 8 of the 15 flights, 4 during a relaxation event and four during upwelling, show significant sub-mesoscale variability in the offshore wind stress distributions (Fig. 3). The first wind relaxation event actually lasted longer near Point Año Nuevo than indicated by the time series at Buoy M2, and spanned 6 days from 2 to 7 August. Especially noteworthy during this time was the wind stress maximum located just to the north of the Point. This feature looks like an atmospheric expansion fan similar to those previously observed in the lee (to the south) of major capes during upwelling-favorable winds (Dorman et al., 1995, 2000; Gan and Allen, 2005; Gan et al., 2005), however such features have not been directly observed during poleward wind events. The maximum wind stresses in these features $\left(0.08 \mathrm{~N} \mathrm{~m}^{-2}\right)$ on August 3rd and 4th were actually much stronger than indicated by the offshore buoys and were counter to the generally held idea that the winds are strongest offshore and weaken as the coast is approached. The weakest winds during the relaxations were near the mouth of the Monterey Bay.

During the upwelling event starting on August 8th, all aircraft observations showed an alongshelf wind stress maximum off Point Año Nuevo (Fig. 3). This maximum was strongest on August 8th and 11 th $\left(>0.16 \mathrm{~N} \mathrm{~m}^{-2}\right)$ and slightly weaker on the 9th and 10th. This clear maximum in the alongshore wind stress may contribute to the formation of the upwelling center off Año Nuevo. Consistent with previous studies, there was a wind shadow behind the coastal mountains in the northeast corner of the Monterey Bay (Graham and Largier, 1997; Ramp et al., 2005). This lead to a very strong gradient in the wind stress extending southwest from Santa Cruz.

To quantify these gradients, the vertical component of the wind stress curl $\mathbf{k} \cdot(\nabla \times \boldsymbol{\tau})$ was computed on the same grid as the wind stress itself (Fig. 4). A planer least-squares fit was used over a circle with radius $15 \mathrm{~km}$ to estimate the curl. During the weak poleward winds on August 4-5, the curl changed sign down the middle of the observing region about $20 \mathrm{~km}$ offshore and was positive (upwelling favorable) offshore and negative (downwelling favorable) nearshore. This may have contributed to the rapid warming of the sea surface $\left(>3^{\circ} \mathrm{C}\right)$ between the 4th and the 5th off Año Nuevo. On August 8,10 , and 11 , there was a region of high positive curl extending southward across the Monterey Bay from Santa Cruz, along the boundary between the unobstructed offshore wind and the wind shadow in the inner bay. Using the conventional formula for Ekman pumping

$$
w_{\mathrm{e}}=\frac{\mathbf{k} \cdot(\boldsymbol{\nabla} \times \boldsymbol{\tau})}{\rho f}
$$

the upwelling velocity $w_{\mathrm{e}}$ was computed where $\rho$ is the water density, $f$ is the Coriolis parameter, and the observed curl maximum $=6 \times 10^{-6} \mathrm{~N} \mathrm{~m}^{-3}$. The result $=5.8 \mathrm{~m} \mathrm{~d}^{-1}$ and was comparable to the upwelling due to coastal divergence at the same time, which was in the range of $5-10 \mathrm{~m} \mathrm{~d}^{-1}$. This indicates that the cold water extending southward across the Monterey Bay during upwelling events may result from the local wind stress curl maximum in addition to the southward advection of cold water from the north. This is consistent with previous results on larger spatial scales that also show that the vertical velocities due to Ekman pumping are comparable to those from Ekman transport near headlands along the central California coast (Pickett and Paduan, 2003).

\subsection{ADCP currents}

The most obvious feature in the observed currents was the preponderance of poleward flow at both locations (Fig. 2). One particularly strong poleward event started on August 3rd at ADCP 2 and August 4 at ADCP 1 . The event was nearly barotropic at both moorings with a slight mid-depth maximum (near $40 \mathrm{~cm} \mathrm{~s}^{-1}$ ), and ended around August 7. The temporal agreement with the August 4-7 wind relaxation appears coincidental, in that poleward flows with this magnitude did not appear during 

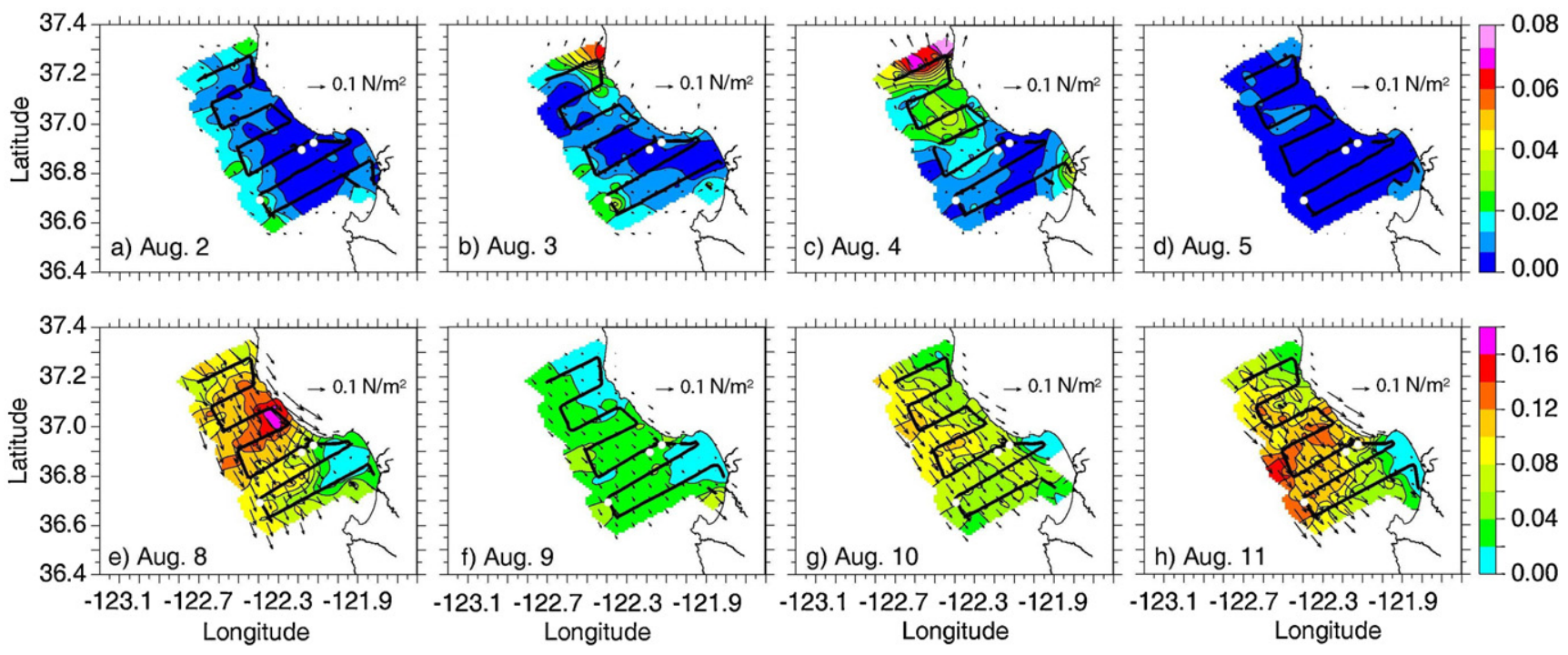

Fig. 3. Time series of the aircraft-observed surface wind stress during (a-d) the August 2-5 wind relaxation event and (e-h) the August 8-12 upwelling favorable event. The white dots indicate the ASAP mooring locations (nearshore) and MBARI buoy M2 (offshore). The units on the color bar are in $\mathrm{N} \mathrm{m}^{-2}$. (For interpretation of the references to color in this figure legend, the reader is referred to the web version of the article.) 


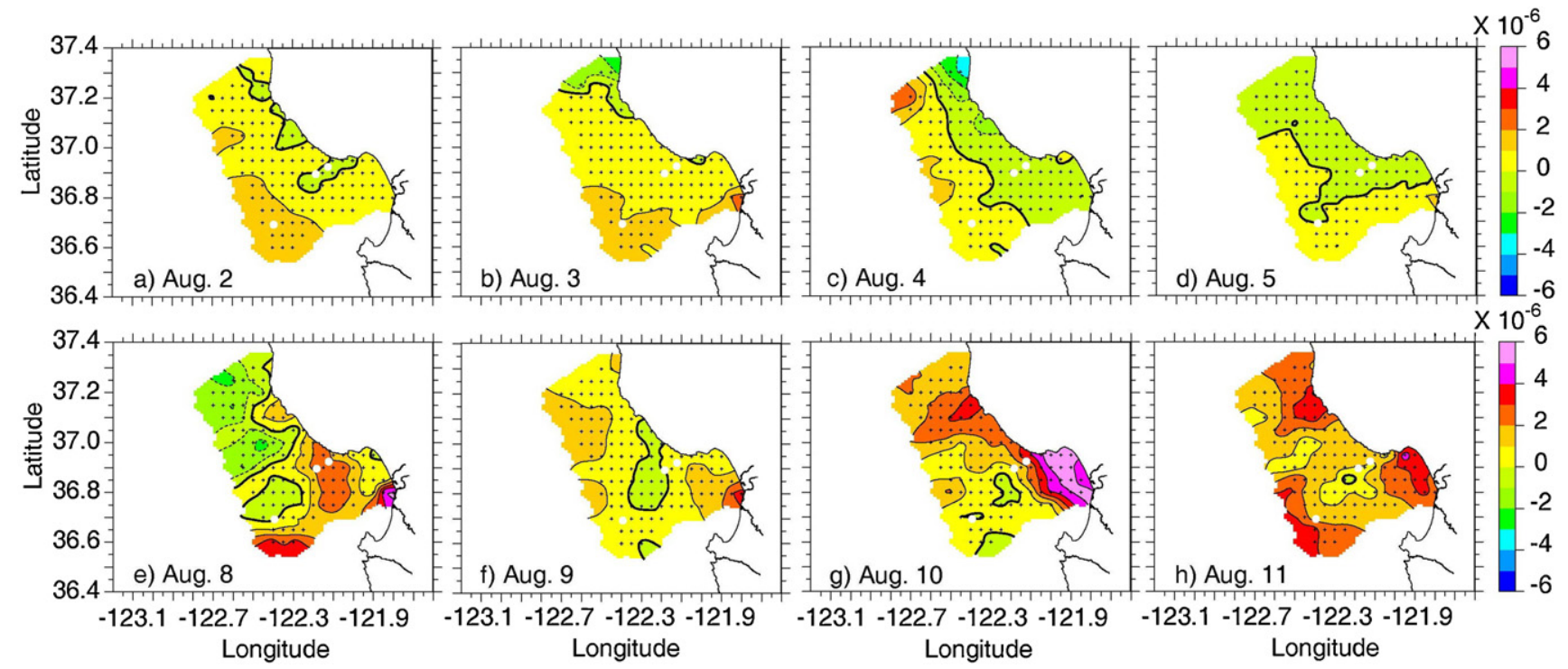

Fig. 4. The vertical component of the wind stress curl computed on the same grid as Fig. 3 . The units on the color bar are in $\mathrm{N} \mathrm{m}^{-3}$. (For interpretation of the references to color in this figure legend, the reader is referred to the web version of the article.) 
the subsequent wind relaxation events. Plan-view displays of the model output, discussed in detail in a later section, gives some indication that this strong poleward event was confined to the continental shelf and was associated with a pulse of warm water exiting the Monterey Bay. There was likewise evidence in the models that the equatorward flow at ADCP 2 centered on August 11-12 was due to this instrument being located in the coastal upwelling jet, while ADCP 1 was located well shoreward of the jet where the flow remained poleward.

Two subsequent, weaker poleward flow events took place from August 19-21 and August 26-28 with no obvious phase lag between moorings. These events were barotropic in nature but had stronger currents near the bottom (order $15 \mathrm{~cm} \mathrm{~s}^{-1}$ ) than the surface (order $5-10 \mathrm{~cm} \mathrm{~s}^{-1}$ ). These poleward flows took place during periods of no winds or weak equatorward winds and thus appear to be wind-related. The vertical current profiles during these times could be modeled as the sum of a barotropic poleward pressure gradient force over the entire water column and weak equatorward Ekman forcing in the upper $20 \mathrm{~m}$. This Ekman flow was clearly observed in the across-shore component as offshore flow (blue colors in Fig. 2) during the stronger upwelling-favorable wind events, as for instance during August 10-11, 16-17, 22-25, and 29-31, most clearly at ADCP 2. In general, ADCP 2 showed more visual correlation with the surface wind stress than ADCP 1 , and this was supported by the spectral analysis (not shown). Significant spectral peaks were observed for periods of 10 days, 5 days, and the tides. A coherence and phase analysis showed that, on average, the 5-10 d winds lead the alongshore currents by $17.9 \mathrm{~h}$ at both instruments. This is close to the local inertial period $(20 \mathrm{~h})$ and represents the spin-up time for the alongshore flow under wind forcing. At ADCP 2, the across-shore currents at the near-surface and near-bottom were coherent with the alongshore wind stress with opposite phase $\left(151^{\circ}\right)$, consistent with Ekman dynamics. At ADCP 1, there was no coherence between alongshore winds and across-shore currents at any depth. This may be due to the coastal constraint, as Ekman turning is reduced the closer the location is to the coast (Ekman, 1905; Ramp and Abbott, 1998).

Also obvious in the plots are the much shorter space and time scales in the across-shore flow vs. the along-shore flow. The across-shore flow was dominated by features order $20 \mathrm{~m}$ vertically and about 2 days in length. There is some suggestion, especially at ADCP 1, that these features were propagating upward. Alongshore currents were statistically well correlated between moorings $(r=.72-.86)$ but across-shore currents were weakly correlated $(r=.3-.5)$. The origin of these smaller-scale acrossshelf motions is not obvious from this data set. The smaller-scale motions may have an alongshore component as well, but it is masked by the larger-scale alongshore flows.

\section{Model/data comparisons}

\subsection{Basic description of the three numerical models}

A key goal of the ASAP program was to collect data sets to improve numerical models for predicting ocean conditions at the scales necessary to resolve coastal upwelling and subsequent plume dynamics. The models were run in near-real time to provide knowledge input to the adaptive sampling decision tree. The three models used were the Harvard Ocean Prediction System (HOPS) (Robinson, 1999; Haley et al., 2009; Haley and Lermusiaux, 2010), the Jet Propulsion Laboratory implementation of the Regional Ocean Modeling System (JPL/ROMS) (Schepetkin and Williams, 2004; Chao et al., 2009; Wang et al., 2009), and the Navy Coastal Ocean Model/Innovative Coastal-Ocean Observing Network (NCOM/ICON) model (Shulman et al., 2009, 2010). Two versions of the HOPS model were examined: HOPS solo (hereafter HOPSs) which had $1.5 \mathrm{~km}$ horizontal resolution, and HOPS nested (hereafter HOPSn) which was nested within HOPSs and had $0.5 \mathrm{~km}$ horizontal resolution (Fig. 5). JPL/ROMS and $\mathrm{NCOM} / \mathrm{ICON}$ had rectangular grid cells near the moorings with about $1.5 \mathrm{~km} \times 2.5 \mathrm{~km}$ horizontal resolution. All the models had 30-32 sigma coordinates in the vertical. While conceptually similar in operation, the models differed significantly in terms of the mixing schemes employed, initial conditions used, and the larger-scale models they were nested within. All four models were forced using surface wind stresses and heat fluxes from the Coupled Ocean/Atmosphere Mesoscale Prediction System (COAMPS ${ }^{\mathrm{TM}}$ ) (Doyle et al., 2009), and assimilated the NPS aircraft SST, glider T and S, and AUV T and S data. The glider data set was one of the largest and most unique data sets available for assimilation. The ten gliders adaptively patrolled the $22 \times 40 \mathrm{~km} \times 1000 \mathrm{~m}$ region under an autonomous 


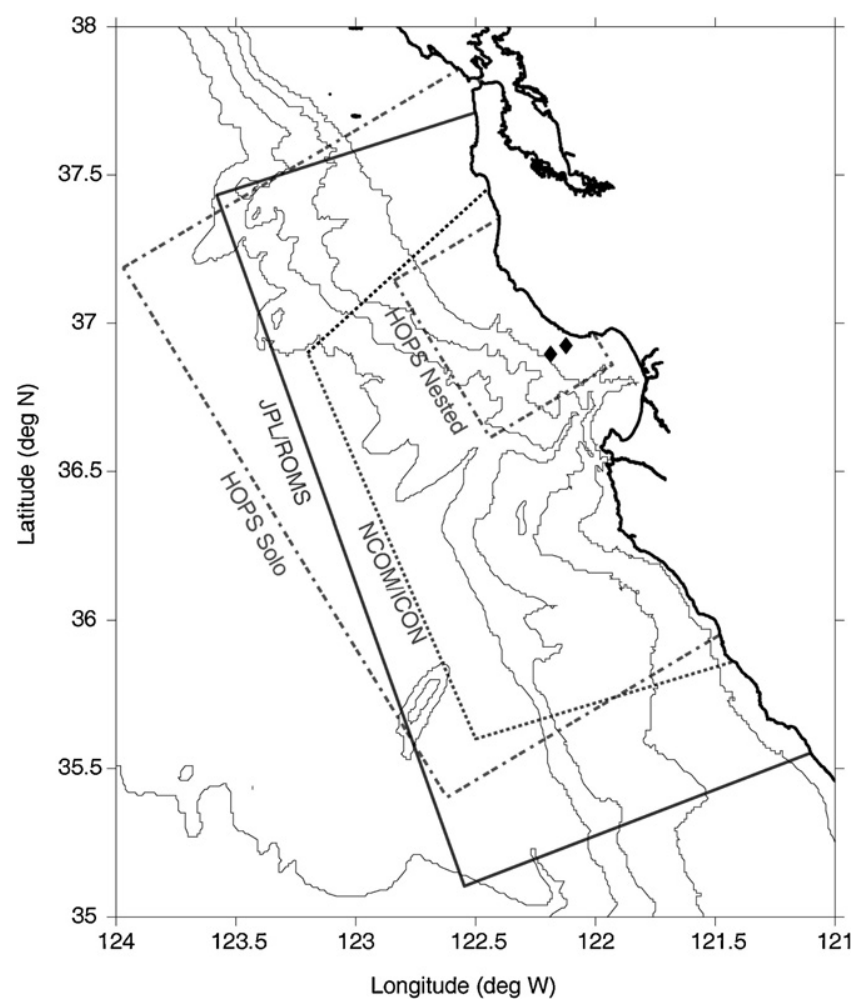

Fig. 5. Model domains off central California for the four numerical models compared against the moored ADCP data on the continental shelf. The mooring positions are indicated by the black diamonds.

coordinated control system (Leonard et al., 2010) programmed to adhere to the $22 \mathrm{~km} \times 2.2 \mathrm{~d}$ length and time correlation scales, respectively. A total of 4530 Spray profiles and 10,619 Slocum profiles were collected. These data did a good job of resolving the eddies and cold filaments within the intensively sampled region. Additionally, the JPL/ROMS model assimilated T and S data from the MBARI buoys M1 and M2. None of the models assimilated velocity from the vehicles, moorings, or coastal HF radar.

The models all use different mixing parameterizations (see references for details). The effect of this on mesoscale model output differences is not obvious, but is limited for short ocean forecasts of a few days or less. Two factors that clearly are important are the model initial and open boundary conditions. Given the small scale of the domain off Point Año Nuevo, the boundary forcing is extremely important to obtaining the correct answer within the model domain. Such well-known features as the California Undercurrent over the continental slope and the barotropic poleward flow over the continental shelf were clearly remotely forced and entered the domain through the open boundaries. The JPL/ROMS model had the longest spin-up time using climatology since July 2003, using boundary conditions from the next-larger ROMS model (5-km) it was nested within. NCOM/ICON likewise used boundary conditions from the next larger nest, called NCOM California Current System (NCOM/CCS). The run was initialized using more recent data starting July 11,2006 . HOPS solo was unique among the three in that is was not nested into a larger-scale model. This model was initialized using local data, that is, the early glider runs and ship surveys from the POINT SUR and the WECOMA conducted in the area, and employed modified Orlanski radiation conditions at the boundaries. All the regional models, either directly or indirectly, made use of satellite products such as sea surface temperature (SST) and surface height (SSH). Some of the runs (such as $5 \mathrm{~km} \mathrm{JPL/ROMS)} \mathrm{assimilated} \mathrm{satellite} \mathrm{data} \mathrm{directly,}$ while the HOPS runs did not assimilate SSH. NCOM/CCS pulled in SSH via an intermediate step, the 
Navy's Modular Ocean Data Assimilation (MODAS) system. This information was thus transferred to the smaller $1.0-1.5 \mathrm{~km}$ nests via the open boundary conditions.

\subsection{Visual comparisons}

To develop a basis for comparison, the output from all four numerical models first underwent the same low-pass filtering and coordinate rotation as the ADCP data. The principal axis ellipses are interesting in their own right: At ADCP 1 the NCOM model overestimated the currents by about $2 \mathrm{~cm} / \mathrm{s}$ relative to both the remaining models and the data, while the ROMS model output was misaligned by $12^{\circ}$ relative to the other estimators (Fig. 6a). At ADCP 2, all the models statistically underestimated the true currents and the HOPSs model had too much energy in the across-shelf component (Fig. 6b).

Three depths were chosen for visual and statistical comparison: near-surface (10,12 m), mid-depth $(24,52 \mathrm{~m})$, and near-bottom $(46,72 \mathrm{~m})$ for $\operatorname{ADCPs}(1,2)$, respectively.

Recall that at ADCP 1, the observed currents consisted of strong poleward flow from 3 to 8 August, followed by equatorward flow from 9 to 17 August, and weakly poleward flow for the remainder of the record (18-31 August). This was true at all depths with limited vertical shear (Fig. 7). The NCOM model fluctuations appeared to lead the data, most noticeably near the surface (Fig. 7a). After mid-August, the NCOM model overestimated the strength of the poleward flow by a factor of 2-4, worse near the surface than near the bottom. The HOPSs model overestimated the poleward flow from 1 to 3 August, missed the equatorward event completely, and also overestimated the second poleward event (Fig. 7a). Like the NCOM model, the model/data agreement improved with depth and near the bottom the agreement was much better than higher in the water column (Fig. 7c). The ROMS model showed better agreement with the data near the surface than the NCOM or HOPSs models but still had difficulty reproducing the equatorward flow. The ROMS currents opposed the observed currents during 9-13 August and were too weak from 13 to 18 August. The ROMS output was the least sheared among the models and looked much the same at all depths (Fig. 7, bottom panels). The HOPSn model showed the best visual agreement with the data. Like HOPSs, the HOPSn time series began with too much poleward flow, perhaps a product of model initialization and the short spin-up time relative to the other two models. Once it got on track, the model produced the August 13-17 equatorward event and had close to the right magnitude for the second poleward event.

The observations at ADCP 2 were more vertically sheared than at ADCP 1 . At ADCP 2, the nearsurface currents were entirely equatorward following the wind stress during August 8-31, while the mid-depth and near bottom currents were poleward from August 18-28 in opposition to the surface flow (Fig. 8, compare a and b). The observed surface currents at ADCP 2 also opposed the surface currents at ADCP 1 from August 18-28, indicating the presence of a velocity front between the two instruments (compare Figs. 7a and 8a). A model's performance will therefore be quite sensitive to its ability to correctly position that front. Like at ADCP 1 , the NCOM model looked good for the first half of the record, again leading the data slightly, but deteriorated during the second half of the month where the surface poleward flow in the model output opposed the observed flow at the ADCP (Fig. 8a). This was perhaps because aircraft and glider data were available to assimilate during August 1-15 but not during August 16-31. The NCOM model and data agreement at ADCP 2 was much better near the bottom where the model captured the poleward/equatorward/poleward transitions although the timing was still off, and there was too little equatorward flow and too much poleward flow at the bottom. The equatorward event was weak in the ROMS model near the surface and absent at the other depths, indicating it misplaced the location of the California Current boundary (Fig. 8a-c). It also badly overestimated the poleward flow after August 18. Like the NCOM model, the currents after August 18 more closely resembled the observations at ADCP 1 than at ADCP 2, indicating that the model placed the velocity front offshore of the observed velocity front. This is consistent with both NCOM and ROMS currents being geographically misplaced a bit too far offshore with respect to the observations. The HOPSs model looked good at the beginning, but then had equatorward rather than poleward flow at mid-depth and near-bottom after August 18 (Fig. 8b, c). The HOPSn model looked the best at site 2 as it did at site 1 . It faithfully produced both the opening poleward and equatorward flow events, and at least had the sign correct at the end. 

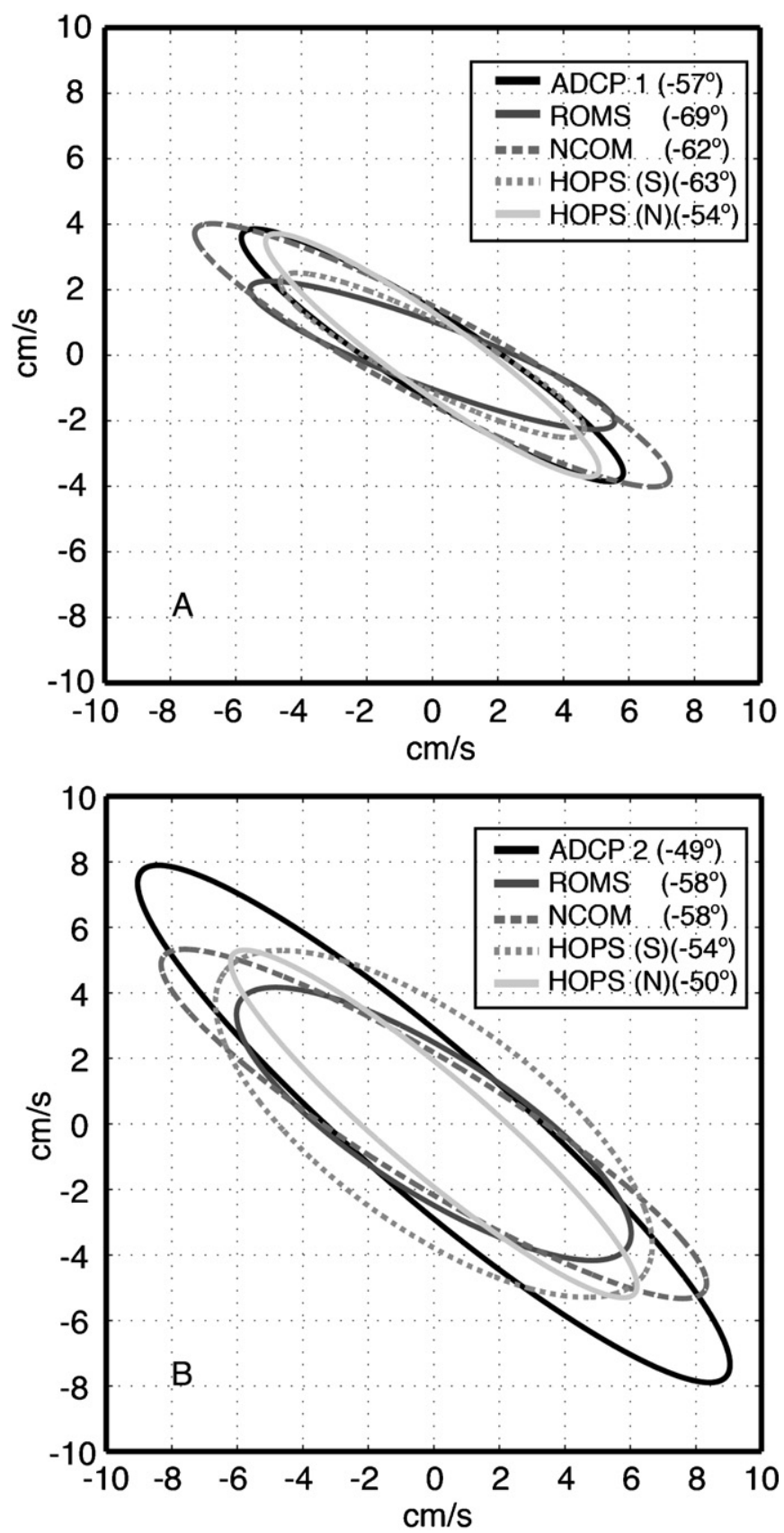

Fig. 6. Mid-water column principal axis ellipses for both models and moorings from: (a) ADCP 1, $34 \mathrm{~m}$ depth; and (b) ADCP 2 , $54 \mathrm{~m}$ depth. North is towards the top of the plot. 

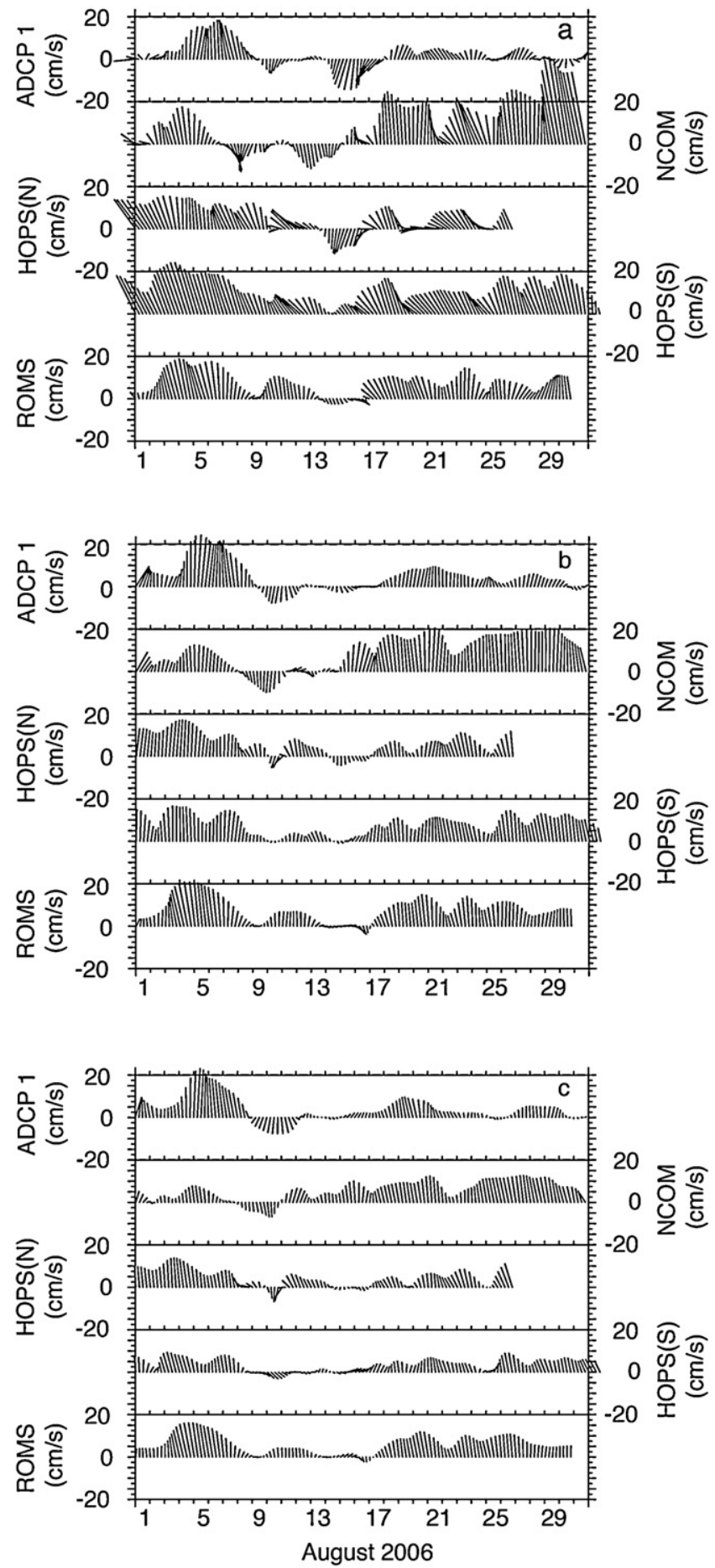

Fig. 7. A comparison of currents from ADCP 1 and the four numerical models for: (a) near-surface (10 m), (b) mid-depth ( $24 \mathrm{~m})$, and (c) near-bottom ( $46 \mathrm{~m})$. Poleward alongshore is up. 

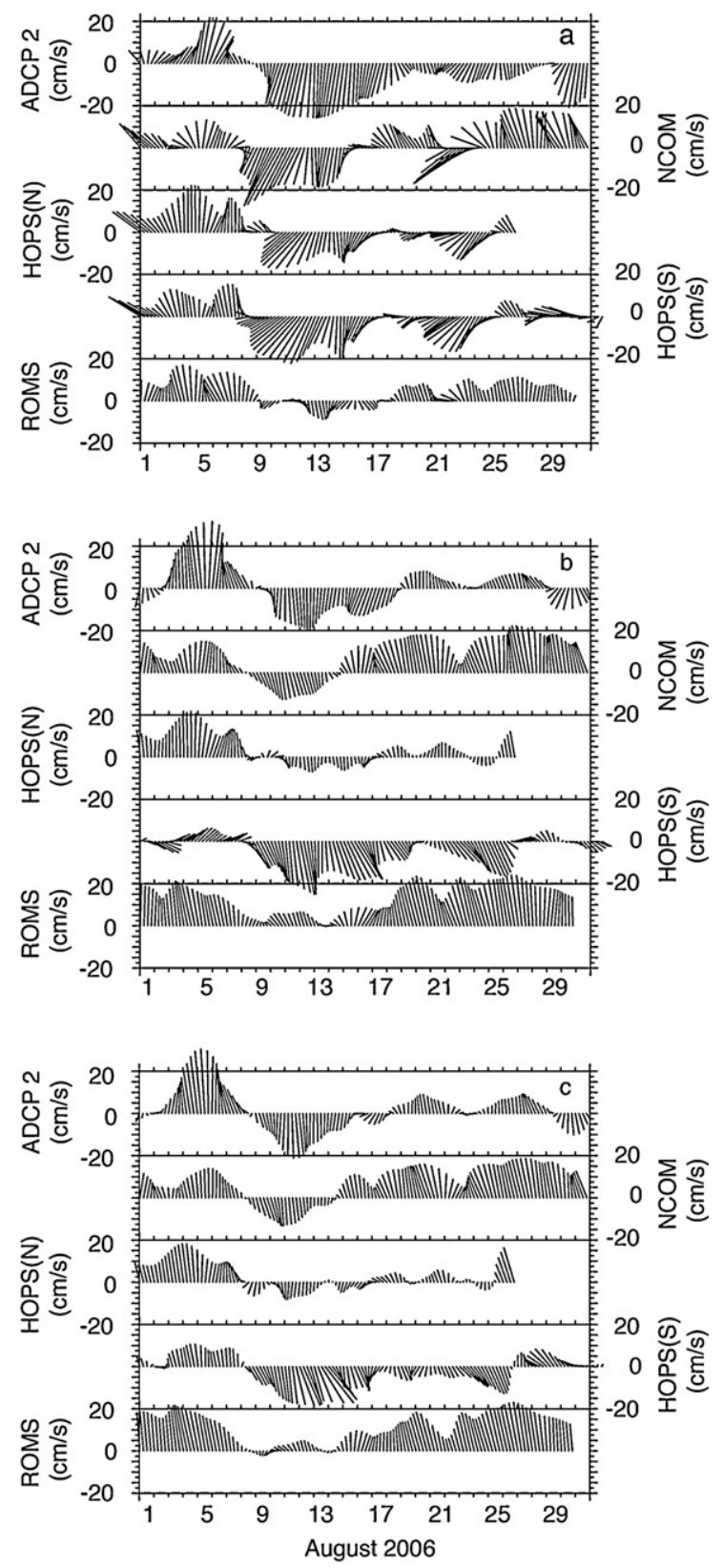

Fig. 8. A comparison of currents from ADCP 2 and the four numerical models for: (a) near-surface (12 m), (b) mid-depth ( $52 \mathrm{~m}$ ), and (c) near-bottom $(72 \mathrm{~m})$.

\subsection{Statistical comparisons}

While already interesting, these stick vector plots form merely an introduction to more quantitative statistical comparisons. The tools used to facilitate these comparisons were the temporal cross-correlation functions and the root mean square (RMS) error between the model output and 
the ADCP data at several grid points surrounding each ADCP location (Fig. 9). The correlations determine if the model output was geographically or temporally displaced from the data, while the RMS error estimates the magnitude of the model/data differences.

For the closest model grid point to the ADCP location and each of the surrounding grid points, the correlation coefficient $\rho_{x y}(\tau)$ was calculated as (Bendat and Piersol, 1986):

$$
\begin{aligned}
& \rho_{x y}(\tau)=\frac{C_{x y}(\tau)}{\sigma_{x} \sigma_{y}} \\
& -1 \leq \rho_{x y}(\tau) \leq 1
\end{aligned}
$$

where $C_{x y}(\tau)$ is the cross-covariance between the model output $(x)$ and the data $(y), \sigma_{x}, \sigma_{y}$ are the variances of series $x$ and $y$, and $\tau$ is the time lag. Significance levels for the correlations were calculated following the method of Amos and Koopmans (1963) using the effective degrees of freedom estimates, $N_{\text {eff }}$, defined as (Davis, 1976):

$$
N_{\text {eff }}=\frac{N}{T_{n}}
$$

where $N$ is the length of the time series in hours and

$$
T_{n}=\sum_{i=-\infty}^{\infty} C_{0}(i \Delta t) C_{n}(i \Delta t) \Delta t
$$

is the correlation time scale for the data. More self-correlated data results in fewer true degrees of freedom and therefore higher significance levels for the correlation coefficient.

When examining the results from these calculations it is important to keep the spatial distribution of the points being compared in mind since they were different for each model (Fig. 9). For the NCOM and both HOPS models, the grid points were oriented along/across-shore while the ROMS model grid was oriented north/south. The HOPSn grid was about 3 times more resolved than the others and less variation is thus expected in the correlation coefficients between these points and the ADCP at

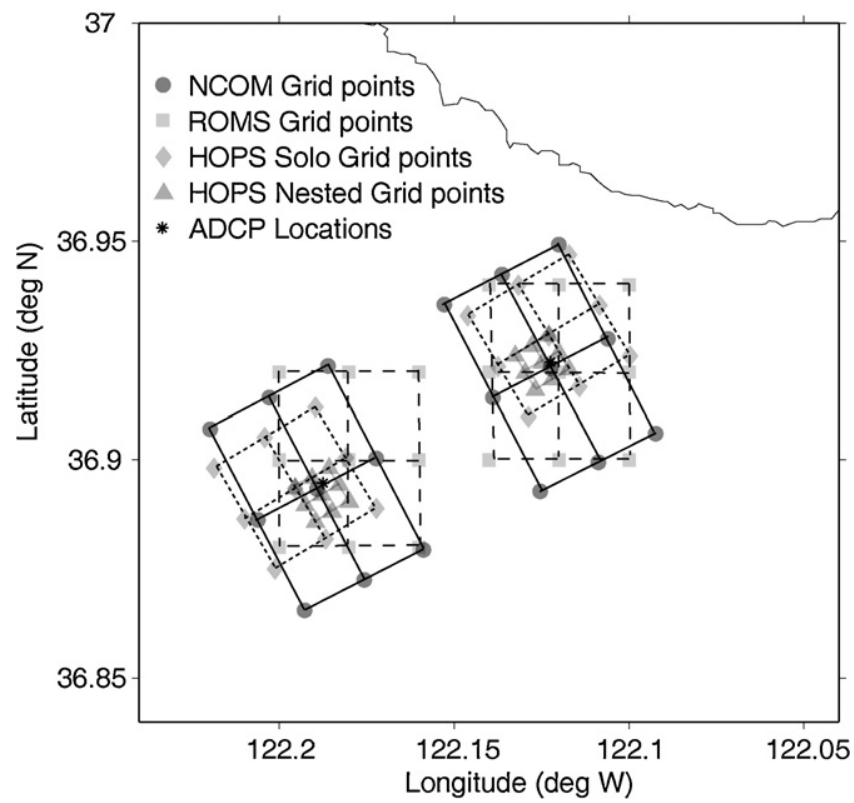

Fig. 9. Grid point locations used to facilitate the spatial correlations, with the ADCP located at the center of each grid as indicated by the asterisk. 
the center. The results (Appendix A) are displayed as box charts showing the correlation, RMS error, and optimum lag time for each of the nine grid points compared to the ADCP located at the center. Statistically insignificant results are shaded, and time lags are presented only for the statistically significant results. A negative (positive) phase means the model leads (lags) the data. An empty box indicates no data, usually because the selected model depth was deeper than the bottom on the inshore side of the mooring. For display, the along- and across-shore components for each model from the grid point closest to the ADCP were compared with the data (Fig. 10). Then, the tables were used to produce component plots of the "best" model/data comparisons for each model using the grid point with the highest correlation shifted relative to the data by the corresponding time lag (Fig. 11). A few robust results emerged from these comparisons.

For the alongshore component, all the models except NCOM at ADCP 1 were significantly correlated with the data. At site 1, the ROMS model produced the highest correlations followed by HOPSs and HOPSn. The ROMS model output was very nearly in phase with the observations while both the HOPS models lead the data by about 16-24 h (Fig. 10, left column). At site 2, the highest correlations were at HOPSn followed closely by HOPSs and ROMS where the correlation levels were quite similar. The HOPSn model lead the data by about $5 \mathrm{~h}$ at the surface but lagged by $16-21 \mathrm{~h}$ subsurface. The HOPSs model also lead the data but by smaller amounts, $0-8 \mathrm{~h}$ for the most correlated points. The phase numbers for ROMS at site 1 were a bit erratic: Choosing the most correlated points, the model was in phase at the surface, lead the data by $22 \mathrm{~h}$ at mid-depth, and lagged by $7 \mathrm{~h}$ at the bottom (Appendix A). In terms of the geographic accuracy, HOPSn at site 2 was consistently better correlated at the NE point rather than at the center point, perhaps indicating a slight misalignment of model features, although the distances were small. None of the other models did consistently better or worse at the other model grid points.

The HOPS nested model was the only one with any skill at reproducing the across-shelf component. Some significant correlations were observed for the ROMS model but they appeared fortuitous since they were $180^{\circ}$ out of phase. At site 2 , the correlations between HOPSn and the data were well above the significance levels (Appendix A) and the visual agreement with the observations was good (not shown). This indicates that HOPSn responded well to the local wind forcing as described earlier from the observations alone, which was more evident at site 2 than at site 1 . The HOPSn across-shore component always lagged behind the observations by longer $(18 \mathrm{~h})$ at mid-depth than at the surface and bottom $(8 \mathrm{~h})$. This is again consistent with a boundary layer response, however it takes too long in the model for the momentum to be transferred to mid-depth. It seems that very high resolution models are necessary to successfully simulate the across-shore component of the flow on the continental shelf in this region. This is likely due to the shorter correlation scales in the across-shelf direction than the alongshelf direction (Ramp et al., 2008).

\section{Discussion}

\subsection{Remote forcing, data assimilation, and boundary conditions}

All three models, with well-established performance at larger space and time scales, had difficulty reproducing the current variability in this small sample region off Point Año Nuevo. One potential explanation is that these small domains cannot correctly capture remote forcing in the form of alongshore pressure gradient forces or coastally trapped waves, which propagate from south to north with the coast on the right in this region. This means that larger-scale features such as these must be captured by the assimilation scheme or fed to the smaller regional-scale models via their boundary conditions.

Considering data assimilation first, the circulation models in ASAP were quantitatively compared with the observed currents at the two ADCP moorings located to the south of the area that was intensively sampled by the gliders and aircraft. Under this configuration, poleward-propagating events of any kind reached the ADCPs ahead of the major sampling area around the upwelling center. The lack of data for assimilation to the south of the ADCPs is one of the reasons why the models represented the effects of the remote forcing differently. All of the real-time models used sequential data assimilation schemes which do not correct initial and boundary fields backward in time. In such a situation, the boundary and initial conditions chosen by the modelers, the data and background covariances 

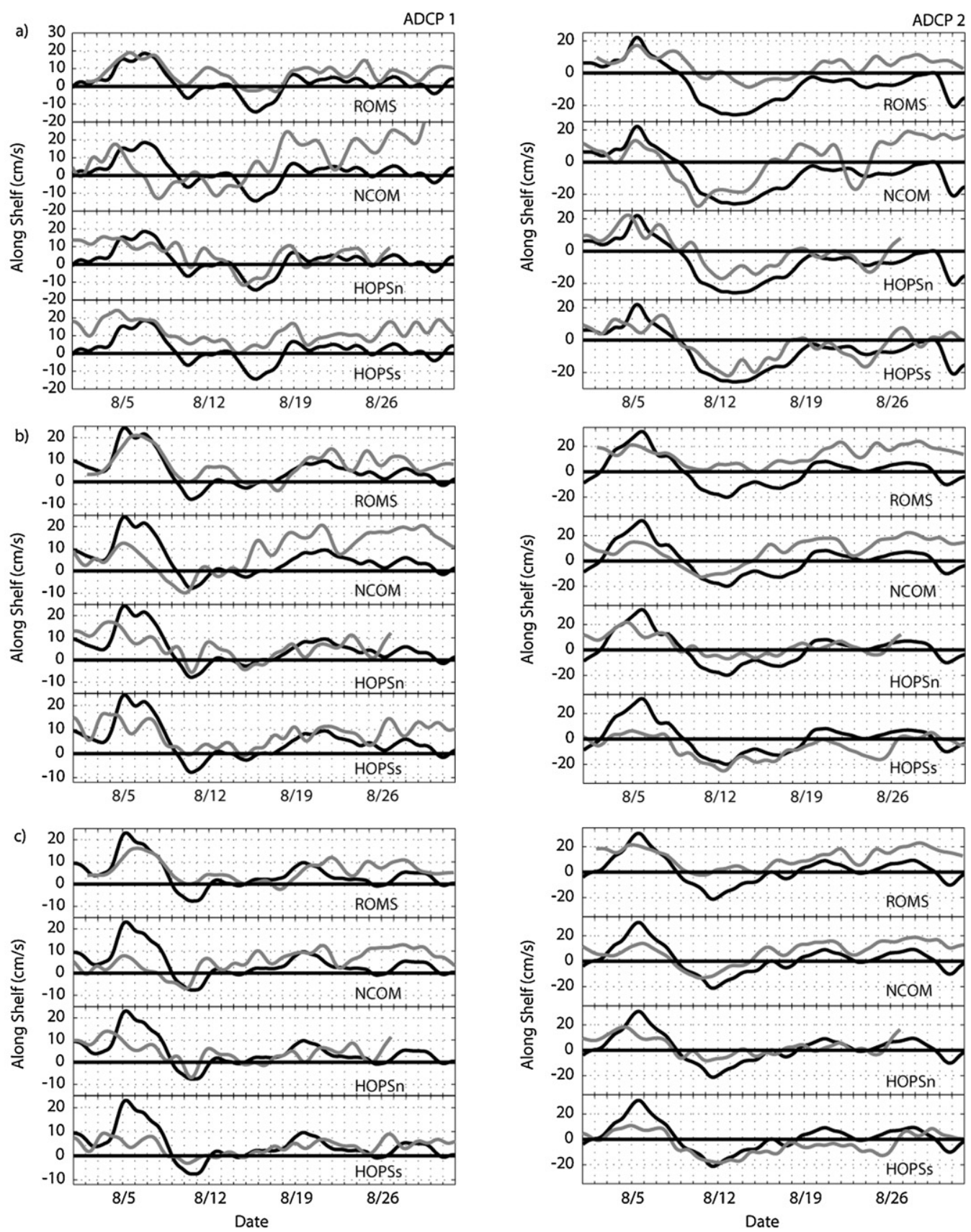

Fig. 10. Model/data (gray/black lines) comparisons for the alongshore current components at ADCP 1 (left column) and ADCP 2 (right column). The three vertical panels for both columns are the comparisons for (a) near-surface (10, $12 \mathrm{~m}$ ), (b) mid-depth $(24,52 \mathrm{~m})$, and (c) near-bottom (46, $72 \mathrm{~m})$. 

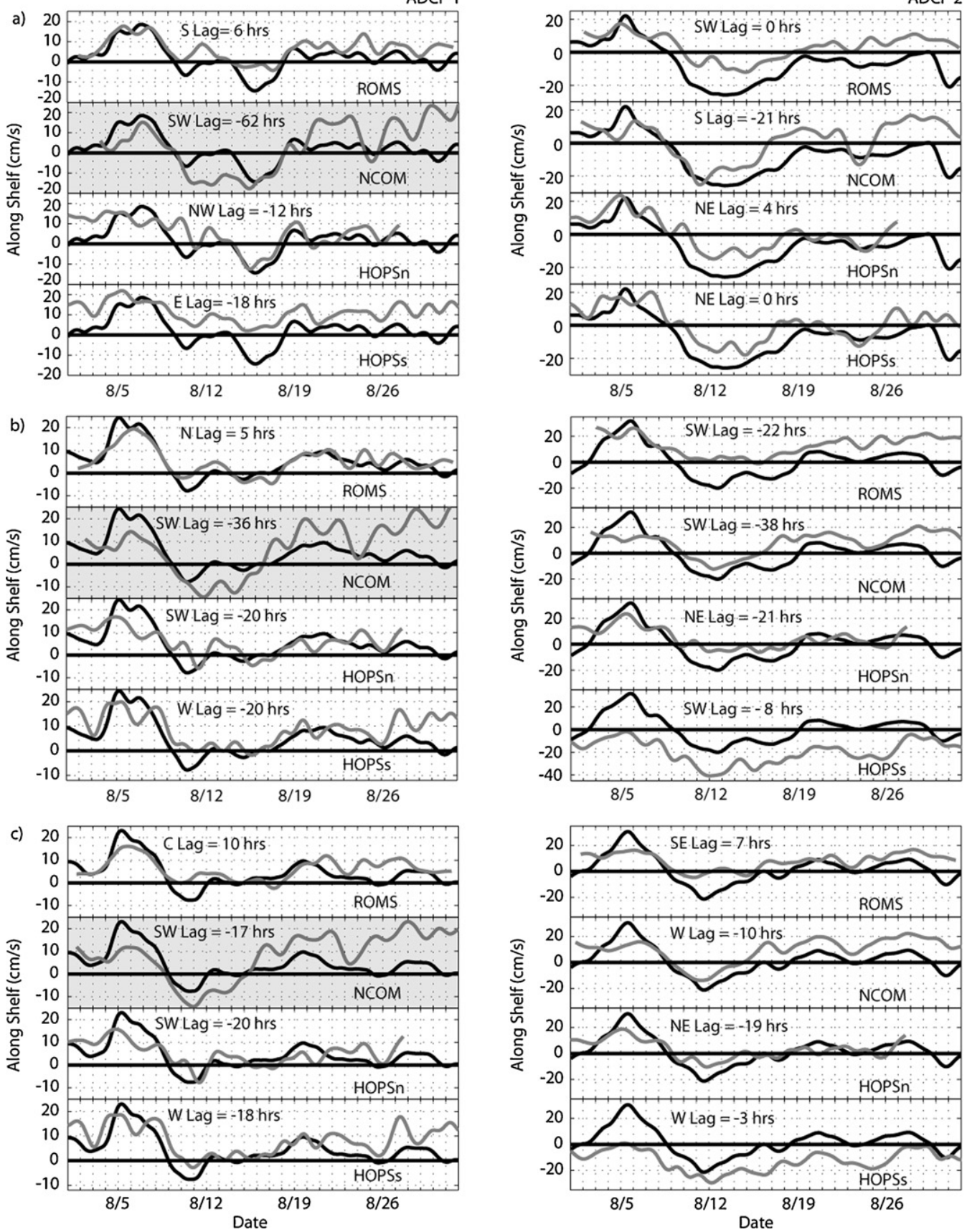

Fig. 11. As in Fig. 10, except the plots are for the grid points (see Fig. 9) and time lags that resulted in the best agreement between the model output and the ADCP data, as judged by the highest correlation coefficient (Appendix A). The notation indicating the position of the winning grid point relative to the ADCP is the same as points on a compass with a " $\mathrm{C}$ " indicating the center point (no geographical offset). The convention for the phase is that a negative (positive) sign means the model leads (lags) the data. For example (upper left panel), the alongshore component of the ROMS model at $10 \mathrm{~m}$ showed the best agreement with the data when the southern grid point was lagged $6 \mathrm{~h}$ in time. The gray shading indicates panels where the correlation coefficient was not statistically significant, but the phase shift was used anyway for completeness. 


\section{REGIONAL NCOM WITH GLOBAL NCOM BC}
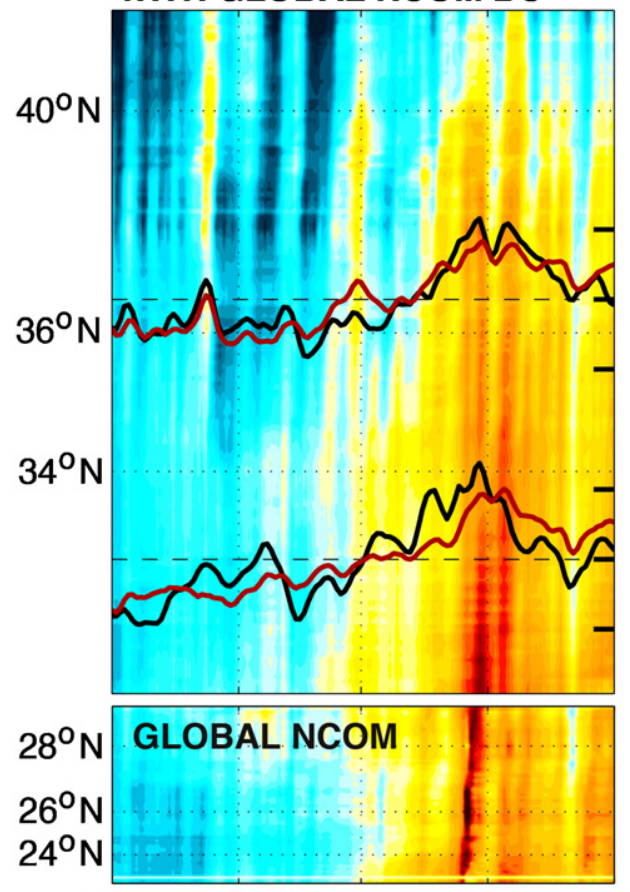

\section{GLOBAL HYCOM}
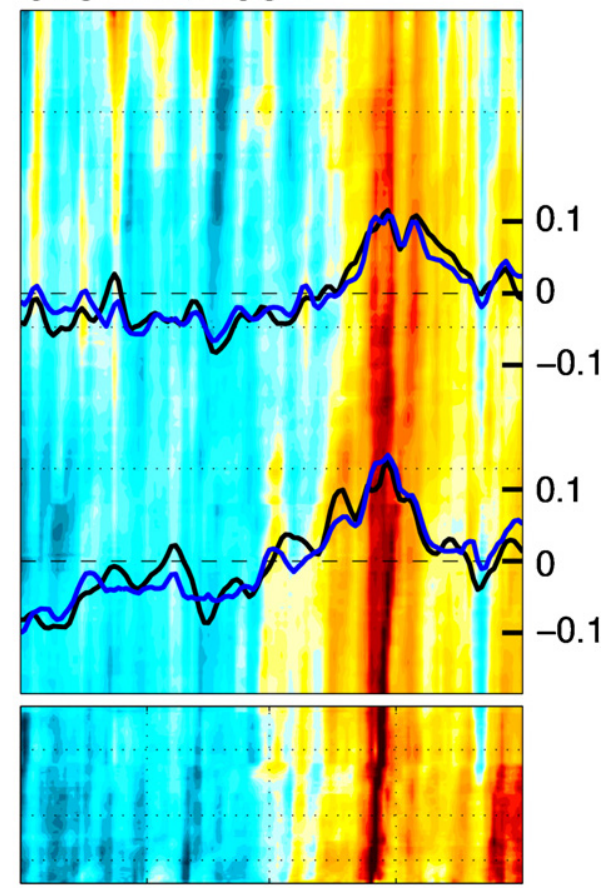

MAY JUN JUL AUG SEP



Fig. 12. Sea surface height (SSH) anomalies from $24^{\circ} \mathrm{N}$ to $40^{\circ} \mathrm{N}$ as computed by (left panel) the Navy regional NCOM CCS model with global NCOM boundary conditions and (right panel) the global HYCOM model. The observed SSH from coastal sea level observations at Monterey $\left(36^{\circ} 36^{\prime} \mathrm{N}\right)$ and San Diego $\left(32^{\circ} 43^{\prime} \mathrm{N}\right)$ are included as the heavy black lines. Time series at the same locations sub-sampled from the two different model configurations are shown as the red (NCOM) and blue (HYCOM) lines, respectively. (For interpretation of the references to color in this figure legend, the reader is referred to the web version of the article.)

used in the assimilation, and the nesting schemes as well as the model resolutions contributed to the differences.

Two of the models, ROMS and NCOM, obtained their boundary conditions from the models they were nested within. The boundaries in HOPSn were obtained from HOPSs, which was initialized using the ASAP opening ship surveys and other available data. The HOPSs boundary conditions were subsequently updated using fits of the model to all available data. To explore the effects of different boundary conditions and coordinate systems, additional model runs were made subsequent to the ASAP program using the Navy's global Hybrid Coordinate Ocean Model (HYCOM) to force the NCOM/ICON model, rather than the global NCOM via the NCOM CCS output. Forcing the same NCOM ICON model directly from the global HYCOM model produced a dramatic improvement in the model/data comparisons: The complex correlations/angular displacements (Kundu, 1976) improved from $0.04 / 52.0^{\circ}$ to $0.69 /-11.5^{\circ}$ at $\mathrm{ADCP} 1$, and from $0.17 / 2.9^{\circ}$ to $0.86 /-4.9^{\circ}$ at $\mathrm{ADCP} 2$. This difference represents a change from essentially no predictive skill to very good predictive skill.

These improvements can be understood by comparing the sea surface height (SSH) anomalies along the California coast calculated from the NCOM/NCOM CCS model and the HYCOM model with the coastal SSH observations (Fig. 12). Both models and the observations show that the SSH anomalies 
during August 2006 were larger than normal and much larger than during AOSN-II in summer 2003 (Ramp et al., 2009; Shulman et al., 2010). Both models also show that these SSH anomalies were propagating poleward at $1-3 \mathrm{~m} \mathrm{~s}^{-1}$, as can be seen by the slope of the maxima (red region) in the latitude vs. time plots (Fig. 12). These anomalies therefore represent remote forcing which will impact the smaller ASAP region off Point Año Nuevo. Comparing the model SSH (red, blue lines) with the observed SSH at Monterey and San Diego (black lines) shows that NCOM/NCOM CCS model underestimated these propagating anomalies with respect to both the observations and the HYCOM model, which closely tracked the observed fluctuations.

Many previous authors have documented poleward-propagating motions along the U.S. west coast in coastal sea level records (e.g. Chelton and Davis, 1982; Denbo and Allen, 1987; Spillane et al., 1987) current meter records (Ramp et al., 1997a) and model output (Pares-Sierra and O'Brien, 1989; Ramp et al., 1997b). For ASAP 2006, a coherence and phase analysis of the observed SSH anomalies relative to the annual mean along the coast during May to October 2006 showed poleward propagation at $2.7 \mathrm{~m} \mathrm{~s}^{-1}$ between Port San Luis and Monterey for oscillations with a 15-day period. Using a simple $c=\omega / k$ relationship where $c$ is the phase speed, $\omega$ is the angular frequency, and $k$ is the horizontal wave number, these fluctuations would have a wavelength of $3695 \mathrm{~km}$ if they were propagating as free waves along the coast. Previous authors found waves along the Big Sur coast in the 29-day band that closely resembled linear, coastally trapped mode- 1 internal Kelvin waves (Ramp et al., 1997a). The dispersion relation for these waves is given by

$$
\omega_{n}^{2}=\frac{N^{2} k^{2}}{k^{2}+(n \pi / H)^{2}}
$$

where $N$ is the Brunt-Väisälä frequency, $n$ is the mode number, $H$ is the bottom depth, and the other variables are as previously defined. Choosing $N=5.5 \times 10^{-3} \mathrm{~s}^{-1}$ as a representative value and $H=1500 \mathrm{~m}$ as a mean depth over the slope, the dispersion relation gives a wavelength of $3490 \mathrm{~km}$ for the 15-day period. The fluctuations observed in both coastal sea level and the Navy models are therefore consistent with coastally trapped mode- 1 internal Kelvin waves. It appears likely therefore that the improvement in the model/data comparisons at ADCP 1 and ADCP 2 with HYCOM nesting were due to that model's more accurate representation of the poleward fluctuations entering the ASAP region from the south. Additional model runs (not shown) changing only smoothed (sigma) vs. un-smoothed (hybrid) bottom coordinates showed improvements using the hybrid coordinates, but these improvements were much smaller than those resulting from using the HYCOM vs. NCOM model. This indicates that the improved boundary conditions were the most important factor in improving the NCOM ICON model performance.

\subsection{Importance of offshore eddies}

Given the relatively good visual and statistical comparisons, a few plan-view plots from the HOPSn model were chosen to illuminate the larger-scale context for the ADCP observed currents (Fig. 13). The first pair on August 4 and 6 (Fig. 13a and b) show the development of the strong poleward flow, one of the most prominent features of the record. The cold water at Point Año Nuevo was quickly swamped by the warm water from the south during this event. The only really strong equatorward flow during August 2006 took place during the days surrounding August 11. This was due to the development of a coastal upwelling jet between the upwelling center and a warm shoreward incursion of the California Current offshore (Fig. 13c). During subsequent upwelling events, as exemplified for instance by conditions on August 23 (Fig. 13d), the upwelling front was located further offshore and the equatorward flow at the two ADCPs was weaker or non-existent. A comparison of Fig. 13a and c supports the conclusion of earlier investigators that the bifurcation of the upwelling plume is closely related to the position and strength of the offshore eddy field. When the eddy was well offshore (Fig. 13a) the cold plume likewise advected offshore. When the eddy was strong and closer to shore (Fig. 13c) the cold plume moved primarily southward. 



17.7

17.3

17.0

16.6

16.3

15.9

15.5

15.2

14.9

14.5

14.2

13.8

13.5

13.1

12.8

12.4

12.1

11.7

11.4
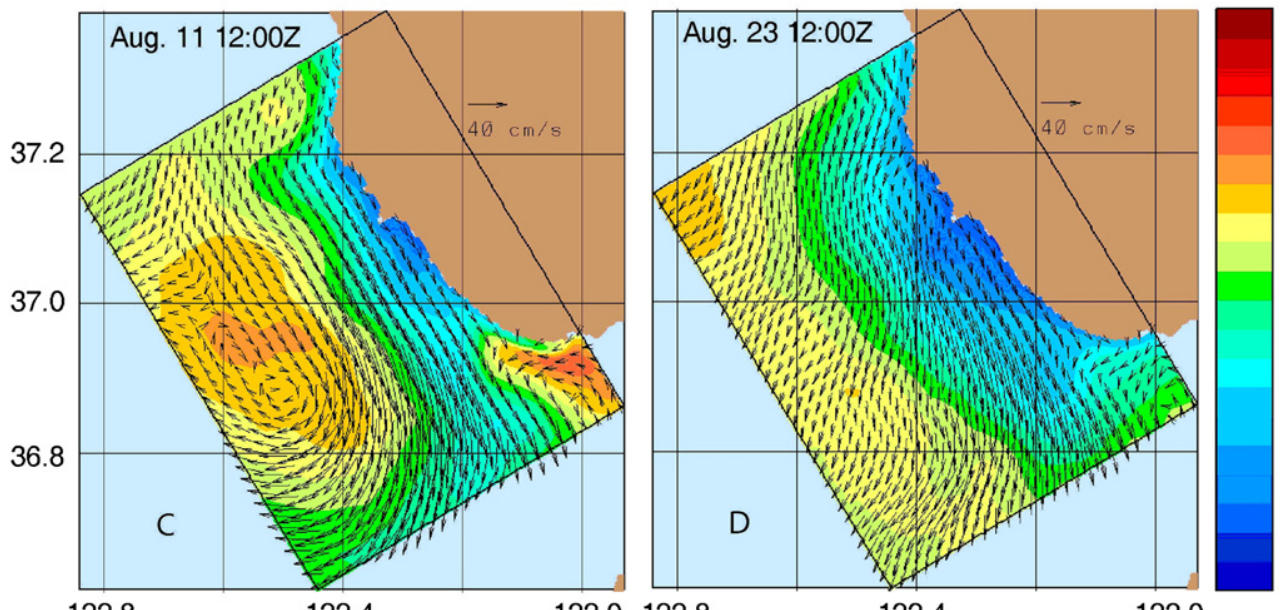

17.7

17.3

17.0

16.6

16.3

15.9

15.5

15.2

14.9

14.5

14.2

13.8

13.5

13.1

12.8

12.4

12.1

11.7

11.4

122.8

122.4

122.0122 .8

122.4

122.0

Fig. 13. HOPSn model currents (black vectors) overlaid on temperature (color bar) for the sea surface layer off Point Año Nuevo for (a) 4 August, (b) 6 August, (c) 11 August, and (d) 23 August 2006. (For interpretation of the references to color in this figure legend, the reader is referred to the web version of the article.)

\section{Summary and conclusions}

The ocean's response to both upwelling and relaxation events was studied for the month of August 2006 near Point Año Nuevo, CA as part of the ASAP MB06 field experiment. An aircraft, several autonomous gliders and AUVS, moored ADCPs, and three numerical models were used to describe the flow. This paper provides a basic description of the flow from the aircraft and moorings and compares those results with numerical simulations from the HOPS, JPL/ROMS, and NCOM models.

The aircraft produced a high-resolution spatial description of the wind stress variability which was previously unavailable for the region. Several new features emerged including the wind stress maximum to the north of the Point during poleward wind events, a clear maximum offshore from the Point during upwelling events, and a strong wind stress curl, also during upwelling favorable events, which could potentially drive upwelling with strength $\left(5-10 \mathrm{~m} \mathrm{~d}^{-1}\right)$ equal to the coastal divergence. This spatial variability in the wind itself likely plays an important role in determining the location 
of 3-D upwelling centers along the west coast of the United States. The wind stress observed at the closest local buoy was often not representative of the actual wind stress off the Point or to the north of the Point and much caution is needed when applying the buoy wind observations to the local coastal oceanography. The MBARI buoy M2 was nevertheless the most representative time series available for the entire month of August since the aircraft was not available after August 15. The buoy recorded upwelling-favorable wind events with approximately equal strength during August $1-3,8-12,16-25$, and 28-31. Poleward winds less than $2.5 \mathrm{~m} \mathrm{~s}^{-1}$ blew during August 4-7, 13-15, and $26-27$.

Despite being only $6.5 \mathrm{~km}$ apart, moorings 1 and 2 responded differently to the sequence of upwelling favorable winds separated by brief relaxations. The flow at site 1 was almost always poleward and often appeared to surge out of the Monterey Bay. Site 2 was just far enough offshore to miss this phenomenon. The site 2 flow was more strongly sheared vertically and more coherent with the local wind stress, especially the across-shore current component with the alongshore wind. Still, there were many times when the currents at site 2 were not coherent with the winds and were instead well correlated with the position of the mesoscale features in the coastal ocean. The strongest equatorward currents were clearly associated with the upwelling jet, and the across-shore position of the jet largely determined the current strength at site 2 , less so at site 1 which was located well inshore of the jet most of the time.

Given the very small scales of motion and the strong shears between the two moorings, it is perhaps not surprising that the three models all had difficulty simulating the flow. The models had more success during the first half of the month when the flow was more wind-driven and there were aircraft data available to assimilate. The models struggled during the second half of the experiment when the flow appeared to be more remotely forced and local observations were lacking. A post-experiment analysis of observed sea level anomalies along the coast and output from the global HYCOM model re-analysis both showed that sea level fluctuations during August 2006 were anomalously strong and propagated poleward with characteristics consistent with free coastally trapped mode- 1 internal Kelvin waves. The failure of the outer-nests driving the open boundaries of the JPL-ROMS and NCOM ICON models to correctly capture these fluctuations may account for many of the observed weaknesses in the model/data comparisons. Subsequent reanalyses of the NCOM ICON model forced by the global HYCOM model, which more accurately represented the coastal sea level variability, showed a dramatic improvement in model predictive skill.

The only model that had any demonstrated skill simulating the across-shore component was the HOPS nested model (HOPSn), which had a three times finer grid resolution than the others ( 0.5 vs. $1.5 \mathrm{~km}$ ). This very fine simulation scale appears to be necessary to correctly place the strong fronts that often occur in the coastal ocean.

\section{Acknowledgements}

Joe Rice (Navel Postgraduate School) arranged and installed the real-time data transmission via the Seaweb network. Marla Stone expertly prepared, deployed, and recovered the moorings. The crew at the NPS Center for Interdisciplinary Remotely-Piloted Aircraft Studies (CIRPAS), under the direction of Bob Bluth and Haf Jonsson, expertly piloted and maintained the TWIN OTTER aircraft. Todd Anderson (NPS) went on every flight to operate the scientific instrumentation package on board. PFJL thanks P.J. Haley and W.G. Leslie for discussions and collaborations. IS thanks S. Anderson and P. Sakalaukus for programming and computer support. This research was carried out in part by the Jet Propulsion Laboratory (JPL), California Institute of Technology, under contract with the National Aeronautics and Space Administration. The authors thank the whole MB06 team for their close collaborations over several years. We thank the Office of Naval Research for support under the MURI-ASAP grants. 


\section{Appendix A.}

Statistical comparisons of the model output at nine grid points with the ADCP time series, colocated at the center of the box. The maximum correlation coefficient at the optimum lag $(\mathrm{h})$, and RMS error between instruments are shown for each comparison. Correlations that are not statistically significant have been grayed out. The across- and alongshore components are shown in the left and right column, respectively. The surface, mid-depth, and near-bottom time series are at the top, middle, and bottom.

\section{NCOM Model}

ADCP 1

Surface Currents $10.25 \mathrm{~m}$

Across-shelf Components

\begin{tabular}{|l|c|c|c|}
\cline { 2 - 4 } Correlation & 0.37 & $\mathbf{0 . 4 5}$ & 0.32 \\
RMS Error & 3.06 & $\mathbf{2 . 5 5}$ & 2.25 \\
$\mathbf{2 4}$ & \\
\cline { 2 - 4 } & & 0.28 & 0.25 \\
& 0.27 & 3.30 & 2.69 \\
4.62 & & \\
\hline & 0.27 & 0.21 & 0.15 \\
6.75 & 6.69 & 7.42 \\
\hline
\end{tabular}

Mid Depth 34.25m Across-shelf Components

\begin{tabular}{|l|c|c|c|}
\cline { 2 - 4 } Correlation & $\mathbf{0 . 4 1}$ & 0.15 & \\
RMS Error & $\mathbf{1 . 4 4}$ & 1.60 & \\
\hline Lag time (hrs) & $\mathbf{0}$ & & \\
\cline { 2 - 4 } & 0.32 & 0.26 & 0.21 \\
1.62 & 1.66 & 1.64 \\
0 & & \\
\hline & 0.22 & 0.20 & 0.18 \\
1.78 & 1.88 & 1.91 \\
\hline
\end{tabular}

Near Bottom 46.25m Across-shelf Components

\begin{tabular}{|c|c|c|}
\hline 0.10 & & \\
1.34 & & \\
\hline 0.37 & 0.19 & \\
1.41 & 1.40 & \\
10 & & \\
\hline 0.35 & $\mathbf{0 . 4 1}$ & 0.38 \\
1.32 & $\mathbf{1 . 3 7}$ & 1.29 \\
10 & $\mathbf{1 1}$ & \\
\hline
\end{tabular}

Correlation RMS Error Lag time (hrs)

Correlation RMS Error Lag time (hrs)

Alongshelf Components

\begin{tabular}{|c|c|c|}
\hline 0.37 & 0.36 & 0.30 \\
9.94 & 9.80 & 6.98 \\
& & \\
\hline 0.39 & 0.40 & 0.38 \\
10.87 & 11.03 & 10.93 \\
& & \\
\hline $\mathbf{0 . 4 4}$ & 0.43 & 0.43 \\
$\mathbf{1 0 . 2 5}$ & 11.00 & 12.90 \\
& & \\
\hline
\end{tabular}

Alongshelf Components

\begin{tabular}{|c|c|c|}
\hline 0.34 & 0.17 & \\
9.80 & 7.36 & \\
& & \\
\hline 0.37 & 0.32 & 0.20 \\
11.34 & 9.82 & 7.63 \\
& & \\
\hline $\mathbf{0 . 3 9}$ & 0.36 & 0.30 \\
$\mathbf{1 0 . 4 8}$ & 11.08 & 10.65 \\
& & \\
\hline
\end{tabular}

\section{Alongshelf Components}

Correlation RMS Error Lag time (hrs)

\begin{tabular}{|c|c|c|}
\hline 0.32 & & \\
6.99 & & \\
\hline 0.38 & 0.25 & \\
9.42 & 7.07 & \\
& & \\
\hline $\mathbf{0 . 3 9}$ & 0.36 & 0.27 \\
$\mathbf{1 0 . 1 3}$ & 9.30 & 7.05 \\
& & \\
\hline
\end{tabular}


NCOM Model

ADCP 2

Surface Currents $12.24 \mathrm{~m}$

Across-shelf Components

Alongshelf Components

\begin{tabular}{|l|l|l|l|}
\cline { 2 - 4 } Correlation & 0.44 & $\mathbf{0 . 4 8}$ & 0.43 \\
RMS Error & 5.78 & $\mathbf{5 . 9 1}$ & 5.32 \\
\cline { 2 - 4 } & & & \\
\cline { 2 - 4 } & 0.44 & 0.45 & 0.41 \\
6.45 & 6.79 & 6.09 \\
\hline & & & \\
\hline & 0.38 & 0.36 & 0.32 \\
& & 7.46 & 7.15 \\
\hline
\end{tabular}

Correlation

RMS Error

Lag time (hrs)

\begin{tabular}{|c|c|c|}
\hline 0.56 & 0.54 & 0.48 \\
12.88 & 13.57 & 14.58 \\
& & \\
\hline 0.59 & 0.58 & 0.52 \\
12.62 & 13.23 & 14.21 \\
-46 & & \\
\hline 0.59 & $\mathbf{0 . 6 4}$ & 0.59 \\
12.56 & $\mathbf{1 2 . 5 2}$ & 13.59 \\
-18 & $\mathbf{- 2 1}$ & \\
\hline
\end{tabular}

Mid Depth 52.24m

Across-shelf Components

Alongshelf Components

Correlation

RMS Error

Lag time (hrs)

\begin{tabular}{|l|l|l|}
\hline 0.33 & 0.32 & 0.35 \\
2.95 & 2.62 & 2.37 \\
\hline $\mathbf{0 . 3 6}$ & 0.36 & 0.35 \\
$\mathbf{2 . 8 1}$ & 2.56 & 2.56 \\
\hline 0.35 & 0.33 & 0.35 \\
2.64 & 2.48 & 2.34 \\
\hline
\end{tabular}

Correlation

RMS Error

Lag time (hrs)

\begin{tabular}{|c|c|c|}
\hline 0.55 & 0.48 & 0.45 \\
13.21 & 13.19 & 13.30 \\
-18 & & \\
\hline 0.58 & 0.54 & 0.48 \\
12.97 & 12.88 & 12.92 \\
-26 & & \\
\hline $\mathbf{0 . 5 9}$ & 0.58 & 0.53 \\
$\mathbf{1 2 . 2 0}$ & 12.61 & 12.43 \\
$\mathbf{- 3 8}$ & -28 & \\
\hline
\end{tabular}

Near Bottom 72.24m

Across-shelf Components

Alongshelf Components

\begin{tabular}{|l|c|c|c|}
\cline { 2 - 4 } Correlation & 0.35 & 0.33 & 0.29 \\
RMS Error & 2.43 & 2.20 & 2.18 \\
\cline { 2 - 4 } & & & \\
\cline { 2 - 4 } & 0.33 & 0.36 & 0.35 \\
2.69 & 2.22 & 2.22 \\
\hline & & & \\
\hline & 0.30 & $\mathbf{0 . 3 9}$ & 0.27 \\
& 2.39 & $\mathbf{2 . 0 4}$ & 2.24 \\
\hline
\end{tabular}

Correlation

RMS Error

Lag time (hrs)

\begin{tabular}{|c|c|c|}
\hline 0.67 & 0.61 & 0.45 \\
9.96 & 9.69 & 10.11 \\
-6 & -9 & \\
\hline $\mathbf{0 . 6 8}$ & 0.64 & 0.55 \\
$\mathbf{1 1 . 4 0}$ & 10.16 & 10.01 \\
$\mathbf{- 1 0}$ & -9 & -14 \\
\hline 0.67 & 0.65 & 0.61 \\
11.45 & 10.96 & 10.37 \\
-14 & -10 & -14 \\
\hline
\end{tabular}




\section{ROMS Model \\ ADCP 1 \\ Surface Currents $10.25 \mathrm{~m}$}

Across-shelf Components

\begin{tabular}{|l|c|c|c|}
\cline { 2 - 4 } Correlation & 0.25 & 0.34 & 0.09 \\
RMS Error & 2.83 & 2.75 & 4.04 \\
Lag time (hrs) & & & \\
\cline { 2 - 4 } & 0.27 & 0.31 & 0.29 \\
3.13 & 2.77 & 3.10 \\
\hline & & & \\
\hline & 0.29 & 0.23 & $\mathbf{0 . 4 4}$ \\
& & 2.71 & $\mathbf{2 . 4 1}$ \\
& & $\mathbf{- 4 9}$ \\
\hline
\end{tabular}

RMS Error

Mid Depth 34.25m

Across-shelf Components

\section{Correlation RMS Error} Lag time (hrs)

\begin{tabular}{|l|l|l|}
\hline 0.34 & 0.34 & \\
1.94 & 1.78 & \\
\hline 0.37 & 0.40 & \\
1.95 & 1.63 & \\
& & \\
\hline 0.40 & 0.40 & $\mathbf{0 . 4 3}$ \\
1.81 & 1.56 & $\mathbf{1 . 4 8}$ \\
\hline
\end{tabular}

Near Bottom 46.25m

Across-shelf Components

Correlation

RMS Error

Lag time (hrs)

\begin{tabular}{|l|l|l|}
\hline $\mathbf{0 . 5 7}$ & & \\
$\mathbf{1 . 9 3}$ & & \\
$\mathbf{- 2 6}$ & & \\
\hline 0.48 & 0.44 & \\
1.84 & 1.25 & \\
\hline 0.36 & 0.38 & \\
2.00 & 1.42 & \\
\hline
\end{tabular}

Correlation

Lag time (hrs)

Correlation

RMS Error

Lag time (hrs)

Alongshelf Components

\begin{tabular}{|c|c|c|}
\hline 0.86 & 0.83 & 0.63 \\
5.05 & 7.43 & 11.82 \\
7 & -3 & -9 \\
\hline 0.83 & 0.86 & 0.74 \\
5.01 & 6.75 & 10.77 \\
9 & 1 & -5 \\
\hline 0.79 & $\mathbf{0 . 8 6}$ & 0.76 \\
5.13 & $\mathbf{5 . 9 4}$ & 10.39 \\
11 & $\mathbf{6}$ & -2 \\
\hline
\end{tabular}

Alongshelf Components

\begin{tabular}{|c|c|c|}
\hline 0.70 & $\mathbf{0 . 8 7}$ & \\
6.77 & $\mathbf{3 . 5 4}$ & \\
6 & $\mathbf{5}$ & \\
\hline 0.66 & 0.82 & \\
7.29 & 4.90 & \\
6 & 4 & \\
\hline 0.62 & 0.78 & 0.85 \\
7.85 & 6.11 & 3.97 \\
& 6 & -5 \\
\hline
\end{tabular}

Alongshelf Components

Correlation

RMS Error

Lag time (hrs)

\begin{tabular}{|c|c|c|}
\hline 0.70 & & \\
6.65 & & \\
11 & & \\
\hline 0.60 & $\mathbf{0 . 7 3}$ & \\
8.13 & $\mathbf{4 . 7 3}$ & \\
11 & $\mathbf{1 0}$ & \\
\hline 0.52 & 0.71 & \\
9.36 & 5.62 & \\
& 12 & \\
\hline
\end{tabular}


ROMS Model

ADCP 2

Surface Currents $12.24 \mathrm{~m}$

Across-shelf Components

\begin{tabular}{|l|c|c|c|}
\cline { 2 - 4 } $\begin{array}{l}\text { Correlation } \\
\text { RMS Error }\end{array}$ Lag time (hrs) & 0.28 & 0.26 & 0.25 \\
& & 3.45 & 3.09 \\
\cline { 2 - 4 } & 0.20 & 0.16 & 0.26 \\
3.93 & 3.98 & 3.49 \\
\hline & & & \\
\hline & 0.21 & 0.29 & $\mathbf{0 . 4 5}$ \\
& 3.92 & 3.71 & $\mathbf{3 . 2 5}$ \\
& & $\mathbf{- 5}$ \\
\hline
\end{tabular}

Alongshelf Components

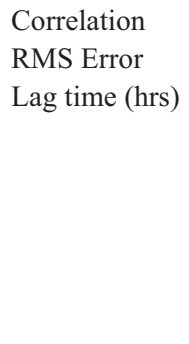

\begin{tabular}{|c|c|c|}
\hline 0.79 & 0.81 & 0.75 \\
13.17 & 13.40 & 15.13 \\
10 & 15 & 23 \\
\hline 0.84 & 0.84 & 0.82 \\
12.77 & 13.28 & 14.29 \\
4 & 9 & 13 \\
\hline $\mathbf{0 . 8 7}$ & 0.87 & 0.85 \\
$\mathbf{1 2 . 0 6}$ & 12.79 & 13.78 \\
$\mathbf{0}$ & 4 & 8 \\
\hline
\end{tabular}

Mid Depth 52.24m

Across-shelf Components

\begin{tabular}{|l|c|c|c|}
\cline { 2 - 4 } Correlation & 0.41 & 0.39 & 0.27 \\
RMS Error & 2.90 & 2.97 & 2.75 \\
Lag time (hrs) & 170 & 175 & \\
\cline { 2 - 4 } & 0.54 & 0.46 & 0.31 \\
& 2.91 & 2.98 & 2.89 \\
178 & 182 & \\
\hline & $\mathbf{0 . 5 8}$ & 0.52 & 0.33 \\
& $\mathbf{2 . 7 4}$ & 2.84 & 2.95 \\
$\mathbf{1 8 1}$ & 184 & \\
\hline
\end{tabular}

Correlation RMS Error Lag time (hrs)

\section{Alongshelf Components}

\begin{tabular}{|c|c|c|}
\hline 0.67 & 0.64 & 0.77 \\
14.96 & 14.66 & $\begin{array}{c}10.91 \\
20\end{array}$ \\
\hline 0.74 & 0.66 & 0.75 \\
14.59 & 15.24 & 11.84 \\
-22 & & 19 \\
\hline $\mathbf{0 . 7 7}$ & 0.71 & 0.73 \\
$\mathbf{1 4 . 2 3}$ & 15.28 & 13.32 \\
$\mathbf{- 2 2}$ & -17 & 9 \\
\hline
\end{tabular}

Near Bottom 72.24m Across-shelf Components Alongshelf Components

\begin{tabular}{|l|c|c|c|}
\cline { 2 - 4 } Correlation & 0.29 & 0.20 & \\
RMS Error & 2.57 & 2.36 & \\
Lag time (hrs) & 172 & & \\
\cline { 2 - 4 } & 0.46 & 0.31 & 0.23 \\
& 2.13 & 2.32 & 1.87 \\
178 & & \\
\hline & $\mathbf{0 . 5 4}$ & 0.42 & 0.19 \\
$\mathbf{1 . 8 2}$ & 2.31 & 2.03 \\
$\mathbf{1 8 0}$ & & \\
\hline
\end{tabular}

Correlation RMS Error Lag time (hrs)

\begin{tabular}{|c|c|c|}
\hline 0.76 & 0.72 & \\
13.21 & 11.65 & \\
-11 & 0 & \\
\hline 0.79 & 0.75 & 0.77 \\
13.21 & 12.21 & 9.50 \\
-17 & -3 & 6 \\
\hline 0.79 & 0.76 & $\mathbf{0 . 7 9}$ \\
13.19 & 13.38 & $\mathbf{9 . 4 9}$ \\
-17 & -9 & $\mathbf{7}$ \\
\hline
\end{tabular}


HOPS Solo

ADCP 1

Surface Currents $10.25 \mathrm{~m}$

Across-shelf Components

\begin{tabular}{l|c|c|c|}
\cline { 2 - 4 } Correlation & 0.34 & 0.12 & 0.21 \\
RMS Error & 4.35 & 4.46 & 3.58 \\
& 1 & & \\
\cline { 2 - 4 } & 0.30 & 0.15 & 0.33 \\
& 5.23 & 5.26 & 4.17 \\
& & & \\
\cline { 2 - 4 } & 0.32 & 0.22 & $\mathbf{0 . 3 8}$ \\
& 5.10 & 4.76 & $\mathbf{4 . 3 0}$ \\
& & $\mathbf{1 0 8}$ \\
\hline
\end{tabular}

Correlation

RMS Error

Lag time (hrs)

Mid Depth 34.25m

Across-shelf Components

\begin{tabular}{l|c|c|c|}
\cline { 2 - 4 } Correlation & $\mathbf{0 . 4 2}$ & 0.24 & \\
RMS Error & $\mathbf{1 . 2 4}$ & 1.30 & \\
\cline { 2 - 4 } & $\mathbf{5 8}$ & & \\
\cline { 2 - 4 } & 0.10 & 0.20 & 0.28 \\
1.62 & 1.74 & 1.33 \\
& & & \\
\hline & 0.10 & 0.31 & 0.23 \\
0.1 .85 & 1.44 & 1.54 \\
\hline
\end{tabular}

Correlation

RMS Error

Lag time (hrs)

\begin{tabular}{|c|c|c|}
\hline 0.75 & 0.78 & 0.78 \\
10.71 & 10.31 & 9.64 \\
-14 & -16 & -18 \\
\hline 0.73 & 0.77 & $\mathbf{0 . 7 9}$ \\
10.48 & 10.90 & $\mathbf{1 0 . 3 0}$ \\
-16 & -17 & $\mathbf{- 1 8}$ \\
\hline 0.71 & 0.76 & 0.78 \\
9.14 & 10.25 & 10.20 \\
-17 & -18 & -19 \\
\hline
\end{tabular}

Alongshelf Components

\begin{tabular}{|c|c|c|}
\hline 0.67 & 0.64 & \\
6.61 & 5.62 & \\
-21 & -24 & \\
\hline $\mathbf{0 . 6 8}$ & 0.67 & 0.62 \\
$\mathbf{6 . 4 6}$ & 6.08 & 5.65 \\
$\mathbf{- 2 0}$ & -21 & -25 \\
\hline 0.68 & 0.68 & 0.67 \\
6.07 & 6.41 & 5.53 \\
-18 & -21 & -22 \\
\hline
\end{tabular}

Near Bottom 46.25m

Across-shelf Components

Alongshelf Components

\begin{tabular}{l|c|c|c|}
\cline { 2 - 4 } $\begin{array}{l}\text { Correlation } \\
\text { RMS Error }\end{array}$ & 0.28 & & \\
& 1.66 & & \\
\cline { 2 - 4 } & 0.39 & 0.18 & \\
& 1.29 & 1.77 & \\
100 & & \\
\hline & $\mathbf{0 . 4 8}$ & 0.29 & \\
& $\mathbf{1 . 3 1}$ & 1.40 & \\
$\mathbf{1 0 1}$ & & \\
\hline
\end{tabular}

Correlation

RMS Error

Lag time (hrs)

\begin{tabular}{|c|c|c|}
\hline 0.63 & & \\
5.53 & & \\
-21 & & \\
\hline $\mathbf{0 . 6 6}$ & 0.59 & \\
$\mathbf{6 . 4 5}$ & 5.10 & \\
$\mathbf{- 1 8}$ & -20 & \\
\hline 0.66 & 0.66 & \\
6.69 & 5.46 & \\
-16 & -17 & \\
\hline
\end{tabular}


HOPS Solo

ADCP 2

Surface Currents $12.24 \mathrm{~m}$

Across-shelf Components

\begin{tabular}{l|c|c|c|}
\cline { 2 - 4 } Correlation & 0.67 & 0.56 & 0.53 \\
Lag Error & 6.32 & 5.41 & 4.02 \\
& 1 & 0 & 0 \\
\cline { 2 - 4 } & 0.66 & 0.59 & 0.54 \\
& 5.50 & 7.63 & 5.19 \\
& 4 & 0 & 0 \\
\hline & $\mathbf{0 . 6 9}$ & 0.66 & 0.59 \\
$\mathbf{4 . 6 3}$ & 6.73 & 6.61 \\
$\mathbf{1}$ & 0 & 0 \\
\hline
\end{tabular}

Alongshelf Components

Correlation RMS Error

Lag time (hrs)

\begin{tabular}{|c|c|c|}
\hline 0.79 & 0.81 & $\mathbf{0 . 8 3}$ \\
8.21 & 8.29 & $\mathbf{9 . 9 9}$ \\
-11 & -7 & $\mathbf{0}$ \\
\hline 0.72 & 0.77 & 0.79 \\
8.52 & 8.52 & 11.13 \\
-16 & 0 & 0 \\
\hline 0.68 & 0.67 & 0.73 \\
9.24 & 9.52 & 12.09 \\
0 & 0 & 27 \\
\hline
\end{tabular}

Mid Depth 52.24m

Across-shelf Components

Correlation

Lag time (hrs)

\begin{tabular}{|c|c|c|}
\hline 0.39 & 0.29 & $\begin{array}{c}0.39 \\
2.20 \\
63\end{array}$ \\
\hline $\mathbf{0 . 4 4}$ & 0.33 & 0.36 \\
$\mathbf{5 . 8 6}$ & 6.08 & 2.64 \\
& & \\
\hline 0.30 & 0.25 & 0.28 \\
24.32 & 13.24 & 5.37 \\
\hline
\end{tabular}

Near Bottom 72.24m

Across-shelf Components

\begin{tabular}{|l|c|c|c|}
\cline { 2 - 4 } Correlation & $\mathbf{0 . 3 7}$ & 0.27 & 0.28 \\
RMS Error & $\mathbf{3 . 7 7}$ & 4.88 & 4.15 \\
Lag time (hrs) & $\mathbf{6}$ & & \\
\cline { 2 - 4 } & 0.34 & 0.30 & 0.20 \\
& 8.11 & 4.24 & 6.91 \\
\hline & 0.22 & 0.21 & 0.15 \\
& 8.13 & 3.93 & 7.05 \\
\hline
\end{tabular}

Correlation

RMS Error

Lag time (hrs)

Correlation

RMS Error

Lag time (hrs)

\begin{tabular}{|c|c|c|}
\hline 0.78 & 0.73 & 0.70 \\
14.20 & 8.41 & 9.38 \\
-8 & -8 & -19 \\
\hline 0.74 & 0.76 & 0.70 \\
10.86 & 10.58 & 8.52 \\
-8 & -5 & -9 \\
\hline $\mathbf{0 . 7 9}$ & 0.74 & 0.71 \\
$\mathbf{2 1 . 4 5}$ & 13.73 & 9.10 \\
$\mathbf{- 8}$ & -2 & -5 \\
\hline
\end{tabular}

Alongshelf Components

Alongshelf Components

\begin{tabular}{|c|c|c|}
\hline 0.78 & 0.75 & 0.73 \\
13.75 & 7.26 & 7.94 \\
-3 & -6 & -15 \\
\hline $\mathbf{0 . 8 1}$ & 0.76 & 0.73 \\
$\mathbf{1 5 . 5 2 2 4}$ & 8.6336 & 7.9259 \\
$\mathbf{- 3}$ & 7 & -7 \\
\hline 0.74 & 0.76 & 0.73 \\
13.61 & 12.44 & 9.88 \\
8 & 7 & 3 \\
\hline
\end{tabular}




\section{HOPS Nested \\ ADCP 1}

Surface Currents $10.25 \mathrm{~m}$

Across-shelf Components

Alongshelf Components

\begin{tabular}{|l|c|c|c|}
\cline { 2 - 4 } Correlation & 0.31 & 0.27 & 0.21 \\
RMS Error & 4.70 & 4.52 & 4.39 \\
\cline { 2 - 4 } & & & \\
\cline { 2 - 4 } & 0.34 & 0.31 & 0.26 \\
4.96 & 4.8305 & 4.62 \\
\hline & & & \\
\hline & $\mathbf{0 . 3 6}$ & 0.33 & 0.29 \\
& 5.04 & 5.00 & 4.84 \\
\hline
\end{tabular}

Correlation

RMS Error

Lag time (hrs)

\begin{tabular}{|c|c|c|}
\hline $\mathbf{0 . 7 1}$ & 0.70 & 0.69 \\
$\mathbf{6 . 4 4}$ & 6.55 & 6.66 \\
$\mathbf{- 1 2}$ & -12 & -12 \\
\hline 0.71 & 0.70 & 0.69 \\
6.34 & 6.49 & 6.68 \\
-12 & -12 & -11 \\
\hline 0.71 & 0.70 & 0.69 \\
6.18 & 6.42 & 6.67 \\
-13 & -12 & -12 \\
\hline
\end{tabular}

Mid Depth 34.25m

Across-shelf Components

Alongshelf Components

\begin{tabular}{l|c|c|c|}
\cline { 2 - 4 } Correlation & 0.55 & $\mathbf{0 . 5 6}$ & 0.56 \\
RMS Error & 1.40 & $\mathbf{1 . 4 0}$ & 1.51 \\
Lag time (hrs) & 10 & $\mathbf{8}$ & 8 \\
\cline { 2 - 4 } & 0.53 & 0.55 & 0.55 \\
& 1.49 & 1.43 & 1.55 \\
10 & 8 & 8 \\
\hline & 0.51 & 0.53 & 0.55 \\
1.60 & 1.54 & 1.58 \\
11 & 9 & 8 \\
\hline
\end{tabular}

Correlation

RMS Error

Lag time (hrs)

\begin{tabular}{|c|c|c|}
\hline 0.69 & 0.69 & 0.689 \\
5.46 & 5.47 & 5.43 \\
-20 & -21 & -21 \\
\hline 0.69 & 0.68 & 0.68 \\
5.45 & 5.50 & 5.49 \\
-20 & -20 & -21 \\
\hline 0.69 & 0.68 & $\mathbf{0 . 6 7}$ \\
5.42 & 5.52 & $\mathbf{5 . 5 3}$ \\
-20 & -20 & $\mathbf{- 2 0}$ \\
\hline
\end{tabular}

Near Bottom 46.25m

Across-shelf Components

Alongshelf Components

\begin{tabular}{l|c|c|c|}
\cline { 2 - 4 } Correlation & 0.26 & $\mathbf{0 . 2 7}$ & 0.26 \\
RMS Error & 1.49 & $\mathbf{1 . 7 2}$ & 1.92 \\
\hline Lag time (hrs) & & & \\
\cline { 2 - 4 } & 0.24 & 0.25 & 0.25 \\
& 1.52 & 1.65 & 1.94 \\
\hline & 0.25 & 0.24 & 0.23 \\
& 1.57 & 1.62 & 2.03 \\
\hline
\end{tabular}

Correlation

RMS Error

Lag time (hrs)

\begin{tabular}{|c|c|c|}
\hline 0.66 & 0.63 & 0.59 \\
5.08 & 5.27 & 5.78 \\
-22 & -21 & -21 \\
\hline 0.66 & 0.64 & 0.60 \\
5.07 & 5.20 & 5.56 \\
-21 & -21 & -20 \\
\hline $\mathbf{0 . 6 7}$ & 0.64 & 0.61 \\
$\mathbf{5 . 0 2}$ & 5.18 & 5.45 \\
$\mathbf{- 2 0}$ & -21 & -20 \\
\hline
\end{tabular}




\section{HOPS Nested}

ADCP 2

Surface Currents $12.24 \mathrm{~m}$

Across-shelf Components

\begin{tabular}{|l|c|c|c|}
\cline { 2 - 4 } Correlation & $\mathbf{0 . 6 4}$ & 0.62 & 0.60 \\
RMS Error & $\mathbf{5 . 1 3}$ & 5.15 & 4.88 \\
Lag time (hrs) & $\mathbf{7}$ & 8 & 9 \\
\cline { 2 - 4 } & 0.62 & 0.61 & 0.59 \\
5.14 & 5.25 & 4.91 \\
8 & 8 & 9 \\
\hline 0.61 & 0.60 & 0.57 \\
5.14 & 5.24 & 4.91 \\
9 & 9 & 9 \\
\hline
\end{tabular}

Mid Depth 52.24m

Across-shelf Components

\section{Correlation \\ RMS Error}

Lag time (hrs)

\begin{tabular}{|c|c|c|}
\hline 0.52 & 0.59 & 0.63 \\
1.94 & 1.81 & 1.68 \\
17 & 17 & 17 \\
\hline 0.52 & 0.61 & $\mathbf{0 . 6 4}$ \\
1.92 & 1.85 & $\mathbf{1 . 6 7}$ \\
17 & 18 & $\mathbf{1 8}$ \\
\hline 0.50 & 0.58 & 0.62 \\
1.93 & 1.91 & 1.74 \\
16 & 18 & 18 \\
\hline
\end{tabular}

Near Bottom $72.24 \mathrm{~m}$

Across-shelf Components

\begin{tabular}{l|c|c|c|}
\cline { 2 - 4 } Correlation & 0.45 & 0.42 & 0.39 \\
RMS Error & 1.93 & 1.72 & 1.85 \\
Lag time (hrs) & 11 & 3 & \\
\cline { 2 - 4 } & 0.48 & 0.44 & 0.41 \\
2.15 & 1.70 & 1.75 \\
14 & 5 & \\
\hline $\mathbf{0 . 5 1}$ & 0.42 & 0.41 \\
$\mathbf{2 . 2 0}$ & 1.82 & 1.70 \\
\hline $\mathbf{1 7}$ & & \\
\hline
\end{tabular}

Alongshelf Components

Correlation

RMS Error

Lag time (hrs)

\begin{tabular}{|c|c|c|}
\hline 0.88 & 0.89 & $\mathbf{0 . 9 0}$ \\
8.14 & 8.36 & $\mathbf{8 . 6 9}$ \\
-6 & -5 & -4 \\
\hline 0.87 & 0.88 & 0.89 \\
8.08 & 8.34 & 8.70 \\
-5 & -5 & -5 \\
\hline 0.86 & 0.87 & 0.89 \\
8.09 & 8.43 & 8.83 \\
-5 & -5 & -5 \\
\hline
\end{tabular}

Alongshelf Components

Correlation

RMS Error

Lag time (hrs)

\begin{tabular}{|c|c|c|}
\hline 0.85 & 0.85 & $\mathbf{0 . 8 6}$ \\
7.83 & 7.77 & $\mathbf{7 . 7 8}$ \\
-18 & -19 & $\mathbf{- 2 1}$ \\
\hline 0.84 & 0.84 & 0.85 \\
7.84 & 7.83 & 7.81 \\
-18 & -19 & -21 \\
\hline 0.84 & 0.84 & 0.85 \\
7.78 & 7.83 & 7.84 \\
-18 & -19 & -21 \\
\hline
\end{tabular}

Alongshelf Components

Correlation

RMS Error

Lag time (hrs)

\begin{tabular}{|c|c|c|}
\hline 0.81 & 0.84 & $\mathbf{0 . 8 6}$ \\
7.02 & 6.67 & $\mathbf{6 . 4 2}$ \\
-13 & -16 & $\mathbf{- 1 9}$ \\
\hline 0.81 & 0.83 & 0.86 \\
7.25 & 6.82 & 6.45 \\
-13 & -16 & -18 \\
\hline 0.80 & 0.82 & 0.85 \\
7.43 & 7.07 & 6.61 \\
-14 & -16 & -17 \\
\hline
\end{tabular}

\section{References}

Amos, D.E., Koopmans, L.H., 1963. Tables of the Distribution of the Coefficient of Coherence for Stationary Bivariate Gaussian Processes. Sandia Corporation, SCR-438.

Beardsley, R.C., Limeburner, R., Rosenfeld, L.K., 1985. WHOI Tech. Rep. 85-35.

Bendat, J.S., Piersol, A.G., 1986. Random Data: Analysis and Measurement Procedures. John Wiley and Sons, New York. 
Chao, Y., Li, Z., Farrara, J., McWilliams, J.C., Bellingham, J., Capet, X., Chavez, F., Choi, J.-K., Davis, R., Doyle, J., Frantaoni, D., Li, P.P., Marchesiello, P., Moline, M.A., Paduan, J., Ramp, S., 2009. Development, implementation and evaluation of a data-assimilative ocean forecasting system off the central California coast. Deep-Sea Research II 56, 100-126, doi:10.1016/j.dsr2.2008.08.011.

Chelton, D.B., 1984. Seasonal variation of alongshore geostrophic velocity off central California. J. Geophys. Res. 89, $3473-3486$.

Chelton, D.B., Davis, R.E., 1982. Monthly mean sea level variability along the west coast of North America. J. Phys. Oceanogr. 12, 757-784.

Davis, R.E., 1976. Predictability of sea surface temperature and sea level pressure anomalies of the north Pacific Ocean. J. Phys. Oceanogr. 6, 249-267.

Davis, R.E., Eriksen, C.E., Jones, C.E., 2002. Autonomous buoyancy-driven underwater gliders. In: Griffiths, G. (Ed.), The Technology and Applications of Autonomous Underwater Vehicles. Taylor \& Francis, London, pp. 37-58, 324 pp.

Denbo, D.W., Allen, J.S., 1987. Large-scale response to atmospheric forcing of shelf currents and coastal sea level off the west coast of North America: May-July 1981 and 1982. J. Geophys. Res. 92, 1757-1782.

Dorman, C.E., Enriquez, A.G., Friehe, C.A., 1995. Structure of the lower atmosphere over the northern California coast during winter. Mon. Weather Rev. 123, 2384-2404.

Dorman, C.E., Holt, T., Rogers, D.P., Edwards, K., 2000. Large-scale structure of the June-July1996 marine boundary layer along California and Oregon. Mon. Weather Rev. 128, 1632-1652.

Doyle, J.D., Jiang, Q., Chao, Y., Farrara, J., 2009. High-resolution real-time modeling of the marine atmospheric boundary layer in support of the AOSNII field campaign. Deep-Sea Research II 56, 87-99, doi:10.1016/j.dsr2.2008.08.009.

Ekman, V.W., 1905. On the influence of the earth's rotation on ocean-currents. Arkiv för Matematik, Astonomi och Fysik 2, 52 pp.

Fairall, C.W., Bradley, E., Rogers, D., Edson, J., Young, G., 1996. Bulk parameterization of air-sea fluxes for tropical ocean-global atmosphere coupled-ocean atmosphere response experiment. J. Geophys. Res. 101, 3747-3764.

Gan, J., Allen, J.S., 2002a. A modeling study of shelf circulation off northern California in the region of the Coastal Ocean Dynamics Experiment 2. Simulations and comparisons with observations. J. Geophys. Res. 107 (C11), doi:10.1029/2001JC001190.

Gan, J., Allen, J.S., 2002b. A modeling study of shelf circulation off northern California in the region of the Coastal Ocean Dynamics Experiment: Response to relaxation of upwelling winds. J. Geophys. Res. 107 (C9), doi:10.1029/2000JC000768.

Gan, J., Allen, J.S., 2005. On open boundary conditions for a limited-area coastal model off Oregon. Part 1. Response to idealized wind forcing. Ocean Model. 8, 115-133.

Gan, J., Allen, J.S., Samelson, R.M., 2005. On open boundary conditions for a limited-area coastal model off Oregon. Part 2. Response to wind forcing from a regional mesoscale atmospheric model. Ocean Model. 8, $155-173$.

Graham, W.M., Largier, J.L., 1997. Upwelling shadows as nearshore retention sites: The example of northern Monterey Bay. Cont. Shelf Res. 17, 509-532.

Haley Jr., P.J., Lermusiaux, P.F.J., Robinson, A.R., Leslie, W.G., Logutov, O., Cossarini, G., Liang, X.S., Moreno, P., Ramp, S.R., Doyle, J.D., Bellingham, J., Chavez, F., Johnston, S., 2009. Forecasting and Reanalysis in the Monterey Bay/California Current Region for the Autonomous Ocean Sampling Network-II Experiment. Special issue on AOSN-II. Deep Sea Res. II, doi:10.1016/j.dsr2.2008.08.010, ISSN 0967-0645.

Haley, P.J., Lermusiaux, P.F.J., 2010. Multiscale two-way embedding schemes for free-surface primitive-equations of the Multidisciplinary Simulation, Estimation and Assimilation System. Ocean Dyn. 60, 1497-1537, doi:10.1007/s10236-010-0349-4.

Kosro, P.M., 1987. Structure of the coastal current field off northern California during the coastal ocean dynamics experiment. J. Geophys. Res. 92, 1637-1654.

Leonard, N.E., Paley, D.A., Davis, R.E., Fratantoni, D.M., Lekien, F., Zhang, F., 2010. Coordinated control of an underwater glider fleet in an adaptive ocean sampling field experiment in Monterey Bay. J. Field Robotics 27, 718-740.

Lentz, S.J., 1987. A description of the 1981 and 1982 spring transitions over the northern California shelf. J. Geophys. Res. 92, 1545-1567.

Lermusiaux, P.F.J., 2006. Uncertainty Estimation and Prediction for Interdisciplinary Ocean Dynamics. Refereed manuscript, Special issue of on "Uncertainty Quantification”. J. Glimm and G. Karniadakis, Eds. J. Comput. Phys. 217, $176-199$.

Lermusiaux P.F.J., Chiu, C.-S., Gawarkiewicz, G.G., Abbot, P., Robinson, A.R., Miller, R.N., Haley, P.J., Leslie, W.G., Majumdar, S.J., Pang, A., Lekien, F., 2006. Quantifying Uncertainties in Ocean Predictions. Oceanography, Special issue on "Advances in Computational Oceanography", T. Paluszkiewicz and S. Harper (Office of Naval Research), Eds., vol. 19, 1, 92-105.

Paduan, J.D., Rosenfeld, L.K., 1996. Remotely sensed surface currents in Monterey Bay from shore-based HF radar (Coastal Ocean Dynamics Application Radar). J. Geophys. Res. 101, 20,669-20,686.

Pares-Sierra, A., O’Brien, J.J., 1989. The seasonal and interannual variability of the California Current system: a numerical model. J. Geophys. Res. 94, 3159-3180.

Pickett, M.H., Paduan, J.D., 2003. Ekman transport and pumping in the California Current based on the U.S. Navy's high-resolution atmospheric model (COAMPS). J. Geophys. Res. 108, 25 pp.

Ramp, S.R., 1989. Moored observations of current and temperature on the shelf and upper slope near Ring 82B. J. Geophys. Res. $94,18,071-18,087$.

Ramp, S.R., Abbott, C.L., 1998. The vertical structure of currents over the continental shelf off Point Sur, CA, during Spring 1990. Deep-Sea Res. II 45, 1443-1470.

Ramp, S.R., Rosenfeld, L.K., Tisch, T.D., Hicks, M.R., 1997a. Moored observations of the current and temperature structure over the continental slope off central California. 1. A basic description of the variability. J. Geophys. Res. 102, 22,877-22,902.

Ramp, S.R., McClean, J.L., Collins, C.A., Semtner, A.J., Hayes, K.A.S., 1997b. Observations and modeling of the 1991-1992 El Niño signal off central California. J. Geophys. Res. 102, 5553-5582.

Ramp, S.R., Paduan, J.D., Shulman, I., Kindle, J., Bahr, F.L., Chavez, F., 2005. Observations of upwelling and relaxation events in the northern Monterey Bay during August 2000. J. Geophys. Res. 110, C07013, 21 pp.

Ramp, S.R., Bahr, F.L., 2006. Seasonal evolution of the upwelling process south of Cape Blanco. J. Phys. Oceanogr. 38 , 3-28.

Ramp, S.R., Davis, R.E., Leonard, N.E., Shulman, I., Chao, Y., Robinson, A.R., Marsden, J., Lermusiaux, P.F.J., Fratantoni, D.M., Paduan, J.D., Chavez, F.P., Bahr, F.L., Liang, S., Leslie, W., Li, Z., 2009. Preparing to predict: The second Autonomous Ocean Sampling Network (AOSN-II) experiment in the Monterey Bay. Deep-Sea Res. II 56, 68-87. 
Rice, J.A., Green, M.D., 2008. Underwater acoustic communications and networks for the U.S. Navy's Seaweb Program. In: Proc. Second International Conference on Sensor Technologies and Applications (SENSORCOMM), Cap Esterel, France, August 25-31, 2008.

Robinson, A.R., 1999. Forecasting and simulating coastal ocean processes and variabilities with the Harvard Ocean Prediction System. In: Mooers, C.N.K. (Ed.), Coastal Ocean Prediction, AGU Coastal and Estuarine Studies Series (77-100). American Geophysical Union.

Rosenfeld, L.K., Schwing, F.B., Garfield, N., Tracy, D.E., 1994. Bifurcated flow from an upwelling center: a cold water source for Monterey Bay. Cont. Shelf Res. 14, 931-964.

Schepetkin, A.F., Williams, J.C., 2004. The Regional Oceanic Modeling System: a split -explicit, free surface, topographyfollowing-coordinate ocean model. Ocean Model. 9, 347-404.

Shulman, I., Rowley, C., Anderson, S., DeRada, S., Kindle, J., Martin, P., Doyle, J., Ramp, S., Chavez, F., Fratantoni, D., Davis, R., Cummings, J., 2009. Impact of glider data assimilation on the Monterey Bay model. Deep-Sea Res. II 56, 128-138.

Shulman, I., Anderson, S., Rowley, C., DeRada, S., Doyle, J., Ramp, S., 2010. Comparisons of upwelling and relaxation events in the Monterey Bay area. J. Geophys. Res. 115, C06016, doi:10.1029/2009JC005483.

Spillane, M.C., Enfield, D.B., Allen, J.S., 1987. Intraseasonal oscillations in sea level along the west coast of the Americas. J. Phys. Oceanogr. 17, 313-325.

Wang, X., Chao, Y., Dong, C., Farrara, J., Li, Z., McWilliams, J.C., Paduan, J.D., Rosenfeld, L.K., 2009. Modeling tides in Monterey Bay, California. Deep-Sea Research II 56, 219-231, doi:10.1016/j.dsr2.2008.08.012.

Winant, C.D., Beardsley, R.C., Davis, R.E., 1987. Moored wind, temperature, and current observations made during Coastal Ocean Dynamics Experiments 1 and 2 over the northern California continental shelf and upper slope. J. Geophys. Res. 92, 1569-1604. 